\title{
ARTÍCULOS
}

\section{PAUTAS ASISTENCIALES DE LOS INMIGRANTES ESPAÑOLES EN RÍO DE JANEIRO Y CIUDAD DE MÉXICO EN PERSPECTIVA COMPARADA. LAS SOCIEDADES DE BENEFICENCIA, SIGLOS XIX Y XX.}

\author{
Alicia Gil Lázaro \\ Universidad de Sevilla \\ agil3@us.es \\ Érica Sarmiento da Silva \\ Universidade do Estado do Rio de Janeiro \\ erisarmiento@gmail.com
}

\begin{abstract}
Resumen: Los españoles fueron una de las comunidades migratorias más numerosas y extendidas por todo el continente americano en la época de la gran oleada de desplazamientos ultramarinos. Este artículo aborda sus pautas asistenciales en perspectiva comparada, en concreto se analiza la temprana fundación de Sociedades de Beneficencia en dos ciudades americanas, Río de Janeiro y Ciudad de México. Además, uno de los objetivos más importantes de estas organizaciones fue la construcción de hospitales que ofrecieran cobertura sanitaria a los afiliados. A través de las memorias anuales de gestión y administración de estas entidades hemos podido comparar su trayectoria hasta tiempos recientes.
\end{abstract}

Palabras clave: Inmigración española, Río de Janeiro, Ciudad de México, asociacionismo migratorio, asistencialismo, Sociedades de Beneficencia, hospitales, perspectiva comparada.

Tittle: WELFARE PATTERNS OF SPANISH IMMIGRANTS IN RIO DE JANEIRO AND MEXICO CITY IN COMPARATIVE PERSPECTIVE. CHARITY SOCIETIES, $19^{\mathrm{TH}}$ AND $20^{\mathrm{TH}}$ CENTURIES.

\begin{abstract}
The Spanish were one of the most numerous and widespread migratory communities throughout the American continent at the time of the great wave of overseas displacements. This article examines their welfare patterns from a comparative perspective, specifically analyzing the early founding of Charitable Societies in two American cities, Rio de Janeiro, and Mexico City. Moreover, one of the most important objectives of these organizations was the construction of hospitals to provide health coverage to their members. Through the annual management and administration reports of these organizations, we have been able to compare their trajectory up to recent times.
\end{abstract}

Keywords: Spanish immigrants, Rio de Janeiro, Mexico City, migratory associationism, welfare, Charitable Societies, hospitals, comparative perspective.

Recibido: $17-06-2021$

Aceptado: 24-06-2021

Cómo citar este artículo: GIL LÁZARO, Alicia y SARMIENTO DA SILVA, Érica. Pautas asistenciales de los inmigrantes españoles en Río de Janeiro y Ciudad de México en perspectiva comparada. Las Sociedades de Beneficencia, siglos XIX y XX. Naveg@mérica. Revista electrónica editada por la Asociación Española de Americanistas [en línea]. 2021, n. 27. Disponible en: <http://revistas.um.es/navegamerica>. [Consulta: Fecha de consulta]. ISSN 1989-211X. 


\section{Introducción}

Desde el trabajo seminal de Samuel Baily en $1982^{1}$, numerosos especialistas han atribuido al mutualismo migratorio y a las asociaciones de carácter benéficoasistencial el protagonismo tanto en la conducción de la ayuda a las comunidades migratorias como en la recreación de un discurso identitario exitoso para la cohesión interna del grupo y sus actividades económicas ${ }^{2}$. Asumiendo estas dos premisas, el propósito de este estudio es realizar una comparación de las prácticas asistenciales entre dos comunidades migratorias españolas —asentada una en Río de Janeiro y en Ciudad de México la otra- y especialmente de sus instituciones benéficosanitarias, en el tiempo de la gran oleada migratoria a América. La finalidad no es otra que obtener un mayor conocimiento sobre el fenómeno del asistencialismo migratorio histórico en las sociedades de destino entre el final del siglo XIX y el inicio del XX, analizando para ello la fundación, desarrollo y principales características de las Sociedades de Beneficencia Españolas establecidas en dichas ciudades, así como su logro institucional más representativo, la erección de hospitales.

Existe hoy en día una amplia bibliografía que se ha ocupado del estudio del asociacionismo migratorio español en el continente americano ${ }^{3}$. La renovación y ampliación temática en los estudios migratorios en los últimos veinte años se ha producido, justamente, a partir de ciertas perspectivas de análisis como la profundización en el estudio del asociacionismo emigrante ${ }^{4}$. Sin embargo, según

\footnotetext{
1 BAILY, Samuel. Las sociedades de ayuda mutua y el desarrollo de una comunidad italiana en Buenos Aires, 1858-1918. Desarrollo Económico. 1982, vol. 21, n. 184, pp. 485-514.

2 ÁLVAREZ, Oscar. Rebuilding virtually the homeland: immigrants' institutions in host countries, between integration and self-preservation. En: ÁLVAREZ, Oscar (ed.). Organización, identidad e imagen de las colectividades vascas de la emigración (siglos XVI-XXI). Bilbao: Universidad del País Vasco, Servicio de Publicaciones, 2010, pp. 73-92; NÚÑEZ, Xosé M. Migrants associations: the Spanish transatlantic experience, 1870-1970. Social History. 2016, vol. 41, n. 2, pp. 136-154.

3 Los últimos años han visto crecer el interés por el asociacionismo migrante a ambos lados del océano. Véanse, tan solo como ejemplos de obras recientes, dentro de un panorama más amplio: SARMIENTO, Érica y EVANGELHO, Dabiel (eds.). Imigração ibérica e associativismo. Identidade e laços de solidariedade. Rio de Janeiro: Editora Autografia, 2021; NUNES DE AZEVEDO, André y SARMIENTO, Érica. O progresso no "Facer as Américas". Sociabilidade e práticas associativas dos imigrantes ibéricos no além-mar (1890-1930). En: SARMIENTO, Érica y PEREIRA, Leandro (eds.). Abordagens cruzadas no mundo Atlântico, Relações contemporâneas entre a Península lbérica e a América Latina. Rio de Janeiro: EDUPE, Autografia, 2019, pp. 23-42; BLANCO, Juan A. y DACOSTA, Arsenio (eds.). El asociacionismo español de una inmigración diferenciada. Madrid: Polifemo, 2020.

${ }^{4}$ Véase el trabajo pionero de FERNÁNDEZ, Alejandro. Mutualismo y asociacionismo. En: VIVES, Pedro; VEGA, María J. y OYAMBURU, Jesús (coords.). Historia general de la emigración española a Iberoamérica. Vol. 1. Madrid: Historia 16, 1992, pp. 331-357. Una visión más reciente en FERNÁNDEZ, Alejandro. El asociacionismo español en Argentina: una perspectiva de largo plazo. En: BLANCO, Juan A. y DACOSTA, Arsenio (eds.). El asociacionismo de la emigración española en el exterior: significación y vinculaciones. Zamora: UNED, 2014, pp. 209-235; para otros destinos véase GONZÁLEZ, Elda y REDONDO, Emilio. Desafíos históricos del asociacionismo español en Brasil: siglos XIX-XXI. En: BLANCO, Juan A. y DACOSTA, Arsenio (eds.). El asociacionismo español... Op. cit., pp. 121-140; KLAUMANN, Marília. Associativismo étnico hispano-brasileiro: histórico e perspectiva atual. En: BLANCO, Juan A. y DACOSTA, Arsenio (eds.). El asociacionismo español... Op. cit., pp. 141-161; BLANCO, Juan A. Desarrollo de la identidad regional: el asociacionismo español en Cuba. En: BLANCO, Juan A. y DACOSTA, Arsenio (eds.). El asociacionismo de la emigración... Op. cit., pp. 129-150.
} 
Xosé M. Núñez Seixas "la enumeración descriptiva de centros, periódicos y asociaciones" ha seguido siendo la tónica dominante ${ }^{5}$. Asimismo, entre las distintas modalidades de asociación étnica, la asistencial ha concitado un interés prioritario, puesto que la asistencia fue, sin lugar a duda, uno de los objetivos fundamentales de las comunidades migratorias de esa época y a pesar de ello todavía es poco lo que conocemos sobre el perfil social y la organización económica de las instituciones.

El asistencialismo, en su versión mutualista o caritativo-benéfica, ha recibido una atención desigual, concentrada sobre todo en las ciudades de destino más importantes como Buenos Aires, São Paulo o La Habana, y también en los colectivos regionales más numerosos como los gallegos, vascos o asturianos ${ }^{6}$. Asimismo, durante mucho tiempo ha predominado el estudio de los aspectos políticos e institucionales, los liderazgos étnicos o las sociabilidades destinadas a compatibilizar las señas de identidad primigenia con aquellas propias de la sociedad de destino. En este sentido, es mucho lo que se ha avanzado en los últimos años en el estudio de estas asociaciones como ámbitos privilegiados desde donde construir la identidad patriótica en la diáspora ${ }^{7}$. Sin embargo, otras perspectivas analíticas, como las que atañen a la gestión y financiación de los organismos o la cobertura asistencial y sanitaria, es decir, la labor de previsión social de la emigración, han quedado tradicionalmente al margen del escrutinio de los historiadores, especialmente en lo que se refiere a la relación e influencia recíproca entre los institutos privados de previsión migratorios y los sistemas sanitarios de los países de destino migratorio ${ }^{8}$.

La inexistencia o difícil acceso a los fondos documentales de los archivos de las instituciones privadas han frenado, seguramente, estudios de mayor calado. Los libros de actas o las memorias fiscales anuales constituyen fuentes de información de primera mano para conocer la actividad asistencial migratoria en el largo plazo y son esenciales en el presente texto. La prensa étnica solía prestar, asimismo, una atención detallada a la vida asociativa y a los liderazgos institucionales. La relación - de colaboración o de conflicto- entre estos organismos privados y los

\footnotetext{
5 NÚÑEZ, Xosé M. Las patrias ausentes. Estudios sobre historia y memoria de las migraciones ibéricas (1830-1960). Gijón: Genueve, 2014, p. 41.

6 Véase FERNÁNDEZ, Alejandro. Inmigración y mutualismo en el largo plazo: el Montepío de Montserrat y las asociaciones catalanas en Buenos Aires. En: BLANCO, Juan A. y DACOSTA, Arsenio (eds.). El asociacionismo español... Op. cit., pp. 241-262; FARÍAS, Ruy. La participación gallega en los inicios del asociacionismo mutualista español en Barracas al Sud (1862-1891). En: BLANCO, Juan A. y DACOSTA, Arsenio (eds.). El asociacionismo de la emigración... Op. cit., pp. 425-442; RAMOS, Jon A. Mutualismo e identidad: ensayo de periodización de la Asociación VascoNavarra de Beneficencia de La Habana, 1877-2012. En: BLANCO, Juan A. y DACOSTA, Arsenio (eds.). El asociacionismo de la emigración... Op. cit., pp. 47-50. Otros estudios fuera de los grandes centros de recepción de españoles: MORALES RAYA, Eva. El asociacionismo de la emigración española en Paraguay (1870-1932): los casos de la Sociedad Española de Socorros Mutuos de Asunción del Paraguay y el Centre Catalá de Asunción. En: BLANCO, Juan A. y DACOSTA, Arsenio (eds.). El asociacionismo de la emigración... Op. cit., pp. 371-383. GIL LÁZARO, Alicia. Las Sociedades de Beneficencia Españolas de México, Puebla y Veracruz en el primer tercio del siglo XX. En: SARMIENTO, Érica y EVANGELHO, Dabiel (eds.). Imigração ibérica... Op. cit. [En prensa].

${ }^{7}$ NÚÑEEZ, Xosé M. y GARCíA, Marcela (eds.). Patrias lejos de casa. Nacionalismo español, migración y exilio en Europa y América (1870-1975). Zaragoza: Prensas Universitarias, 2020.

8 BERNARDO DE QUIRÓS, Pilar. EI 'momento mutualista' en la formulación de un sistema de protección social en Argentina: socorro mutuo y prevención subsidiada a comienzos del siglo XX. Revista de Indias. 2013, n. 257, pp. 157-192.
} 
representantes diplomáticos o las autoridades locales también generó huellas documentales en los archivos públicos estatales. Finalmente, las obras conmemorativas, editadas por los propios establecimientos que han sobrevivido hasta tiempos recientes, funcionan a menudo como una fuente de información más, que permite a los investigadores acercamientos alternativos, si bien es usual que compartan un carácter esencialmente laudatorio y acrítico ${ }^{9}$.

Para caracterizar la asistencia y a los asistidos, es necesario recordar, de entrada, que las asociaciones creadas en el continente americano solo incluían a una parte de los inmigrantes y su perfil social no siempre era representativo del conjunto. Los hombres y los sectores medio-altos y medios de las comunidades solían estar sobrerrepresentados y solo un veinte o 25 por ciento de los varones mayores de edad se asociaba a una entidad étnica ${ }^{10}$. El estudio de las sociedades benéficas y sus hospitales abre la puerta al conocimiento de los sujetos sociales que las crearon y mantuvieron por largo tiempo; sin embargo, las huellas documentales son más generosas en imágenes y discursos propios de los grupos dirigentes que de los afiliados "de a pie" y suelen dejar fuera, claro está, a todos aquellos que no pudieron afiliarse a estos sistemas de solidaridad y mutualismo migratorio.

Desde una perspectiva metodológica comparativa ${ }^{11}$ y partiendo de las premisas citadas, el texto se organiza en dos partes. En primer lugar, es necesario identificar a estas dos comunidades a través de ciertas variables demográficas como el tamaño de los grupos, frente a la población local y frente a otros colectivos extranjeros; sus lugares de origen, las ocupaciones y pautas asociacionistas habituales. En segundo lugar, partimos de la base de que las colectividades españolas de Ciudad de México y Río eligieron el modelo benéfico asistencial como la fórmula principal de solventar sus necesidades de apoyo solidario intracomunitario frente a otras soluciones como las Asociaciones de Socorros Mutuos. Por tanto, el foco de atención se dirigirá en concreto hacia las Sociedades de Beneficencia fundadas por estos dos grupos, sus características, principales objetivos asistenciales, evolución, funcionamiento económico y la cobertura sanitaria a través de la fundación de hospitales propios.

9 CARREÑ̃, Alberto M. Los españoles en México (Un siglo de Beneficencia). México, 1942; MATUTE, Ángel. Historia y evolución social de la Beneficencia Española en México. México: s.p.i., 1966; LORENZO LAGUARTA, Pablo. Historia de la Beneficencia española en México (síntesis). México: La Impresora Azteca, 1955; DANZA GRECO, Patricia. Un olhar sobre o pasado. As origens da SEB e da Imigração española no Brasil. Revista do Hospital Espanhol. Edição Especial. Abr. 2010; Sociedade Espanhola de Beneficencia: 150 años de história. Rio de Janeiro: Sociedade Espanhola de Beneficencia, 2009.

10 NÚÑEZ SEIXAS, Xosé M. Migrants associations... Op. cit., p. 142.

11 LEVINE, Philippa. Is comparative history possible? History and theory. 2014, n. 53, pp. 331-347. EI método comparativo, como una práctica profesional y disciplinar y una herramienta con la que escribir la historia, ofrece un enorme potencial para el conocimiento de la historia, dada la posibilidad que abre de evaluar procesos históricos paralelos en el tiempo pero en distintas naciones o unidades políticas territoriales, de tal manera que permitan establecer qué es lo verdaderamente particular en ellos y qué es lo común en los distintos escenarios y qué hechos son en realidad resultado de procesos de un alcance mayor, regional o incluso global. 


\section{Los inmigrantes españoles en Ciudad de México y Río de Janeiro}

Tanto Río de Janeiro como Ciudad de México experimentaron a fines del siglo XIX y principios del XX un proceso acelerado de transformaciones impulsado por el afán modernizador de sus élites, que concibieron a ambas ciudades como la vitrina expositora del desarrollo económico alcanzado en los años a caballo entre los dos siglos. A pesar de los numerosos avatares sociales, económicos y políticos del Porfiriato en México y la instauración de la República en Brasil, se puede afirmar que las dos capitales eran bastante prósperas ${ }^{12}$.

El crecimiento económico asociado al sector agroexportador favoreció los avances en la urbanización y un gradual desarrollo de los servicios públicos, los transportes, las comunicaciones, el alumbrado y las obras de saneamiento. La condición de capitalidad atrajo en las dos urbes fuertes inversiones en infraestructuras, sobre todo ferroviarias, mientras que propició una concentración de actividades económicas que hizo de ellas dos de los más poderosos centros mercantiles de la América Latina del norte y del sur, al tiempo que fortalecía sus circuitos financieros hasta convertirlos en ejes centrales de sus respectivas finanzas nacionales ${ }^{13}$.

La acumulación de capital provino del sector cafetalero de la provincia de Río de Janeiro, y el azucarero y siderometalúrgico, entre otros, en las regiones aledañas a Ciudad de México. Esto favoreció en ambos casos la industrialización, la formación de fuertes mercados consumidores internos y la atracción de mano de obra. Los gobiernos centrales incentivaron las inversiones y concedieron créditos a la actividad económica y, así, tanto Río como Ciudad de México se convirtieron en centros productores de tejidos, bebidas, alimentación y otros productos, además de conocer un importante desarrollo del sector de la construcción civil y un crecimiento igualmente fuerte de los servicios. El ferrocarril y el transporte a vapor experimentaron una gran expansión en el cambio de siglo, lo que convirtió a las dos ciudades en núcleos distribuidores y abastecedores que articulaban distintos mercados regionales.

Mientras en Río se impulsaba la Grande Reforma Urbana bajo la presidencia de Rodrigues Alves entre 1903 y 1906 - cuyo objetivo era atraer mano de obra europea al país-Ciudad de México se hallaba inmersa, por esas mismas fechas, en los preparativos para los fastos del primer Centenario de la Independencia, que se celebró en 1910, coincidente con la caída del régimen del octogenario Porfirio Díaz. El rostro de las dos ciudades cambiaría enormemente con esos procesos, pero aún con este anhelo de modernidad por bandera, ninguna de ellas pudo evitar que crecieran en su seno fuertes contrastes entre riqueza y pobreza, zonas modernas y otras apegadas a su origen rural, amplias bolsas de marginalidad y crecientes

\footnotetext{
12 SPECKMAN, Elisa y AGOSTONI, Claudia. Modernidad, tradición y alteridad. La ciudad de México en el cambio de siglo. México: UNAM, 2000 LAHMAYER, Eulália. Historia de Rio de Janeiro (do capital comercial a o capital industrial e financiera). Rio de Janeiro: IBMEC, 1978, pp. 450-503.

13 CERUTTI, Mario. Empresarios españoles y sociedad capitalista en México (1840-1920). Gijón: Archivo de Indianos, 1995, pp. 83-99; AZEVEDO. André Nunes. A grande reforma urbana do Rio de Janeiro: Pereira Passos, Rodrigues Alves e as ideias de civilização e progresso. Rio de Janeiro: Editora PUC-Rio; Mauad X, 2017.
} 
problemas de delincuencia, de los que no fueron ajenos los inmigrantes llegados a una y otra ${ }^{14}$.

\subsection{El tamaño de las dos comunidades españolas}

En el contexto de crecimiento y centralidad económica que vivieron las dos capitales en las décadas finales del siglo XIX, todos esos cambios radicales - tanto de orden cualitativo como de orden cuantitativo- tuvieron su correlato en términos demográficos. A partir de la década de 1870 sus respectivas poblaciones comenzaron a crecer, en un proceso que continuaría a lo largo del siglo XX. Los censos de la capital mexicana muestran que esta contaba alrededor de doscientas mil almas en 1870. Una década más tarde había crecido a doscientas cincuenta mil; en el censo de 1900 la población se acercaba a trescientos cincuenta mil habitantes y en 1910 llegó a alcanzar los 471 mil. Once años después, concluida la etapa armada de la revolución, la población de la capital según el censo de 1921 era de 615367 habitantes $^{15}$.

En 1872, la población en Río de Janeiro partía de niveles relativamente similares a los de Ciudad de México, pues el censo mostraba una población de 274972 habitantes. Pero muy pronto el ritmo de crecimiento se disparó, de manera que en 1890 ya superaba el medio millón; la cifra volvía a elevarse en 1906, hasta los 811443 moradores, con lo cual doblaba el tamaño de la población de Ciudad de México en 1910, y un nuevo ascenso en 1920 elevó la cifra a $1157873^{16}$. Por tanto, Río había tomado claramente la delantera frente a la otra ciudad, mucho antes de la revolución ${ }^{17}$.

De manera similar en los dos casos, Río y México se convirtieron en las ciudades más pobladas de sus países en este período. Según Érica Sarmiento, en el crecimiento de Río a principios del siglo XX tuvo una influencia clave la abolición de la esclavitud en 1888 y el éxodo rural masivo de exesclavos hacia la capital, así como de individuos libres desposeídos. El fin de la esclavitud también impactó en el aumento de la demanda de mano de obra inmigrante, entonces considerada más

\footnotetext{
14 SARMIENTO, Érica y MEDEIROS DE MENEZES, Lená. Aspectos da desordem urbana: imigrantes ibéricos e a contravenção no Rio de Janeiro republicano (1880-1930). Estudos Ibero-americanos. 2015, vol. 41, n. 1, pp. 164-180; GIL LÁZARO, Alicia. Extranjeros perniciosos. Infractores y delincuentes españoles en la Ciudad de México, 1910-1936. Revista de Indias. 2003, vol. LXIII, n. 228, pp. 477-494.

15 MORALES, María D. La expansión de la ciudad de México en el siglo XIX. El caso de los fraccionamientos. En: MORALES, María D. [et al.]. Investigaciones sobre la historia de la ciudad de México III. México: INAH, 1978, p. 81.

${ }^{16}$ NUNES DE AZEVEDO, André y SARMIENTO, Érica. Las 'parroquias' en la ciudad de Rio de Janeiro: vivienda y trabajo de los gallegos en el barrio de San Antonio (1850-1930). Andes. 2017, vol. 28, n. 2.

17 Aunque un importante crecimiento natural caracterizó la dinámica demográfica mexicana del período porfiriano (la transición demográfica hizo aumentar la población en más de seis millones de personas en términos absolutos a lo largo del período), un fenómeno demográfico nuevo, el éxodo de mano de obra rural mexicana hacia los Estados Unidos, comenzó a partir de la década de 1850 (y también hacia Guatemala, aunque en menor escala, y a fines de siglo XIX). LIDA, Clara. Inmigración y exilio. Reflexiones sobre el caso español. Madrid: Siglo XXI Editores, 1997, p. 35.
} 
productiva y, al mismo tiempo —dentro de las teorías raciales entonces vigentessuperiores desde el punto de vista intelectual ${ }^{18}$. Un flujo continuo de población campesina del interior del país llegó igualmente a la capital mexicana, atraído por el auge económico y las mayores oportunidades de trabajo y de vida que esta ofrecía.

El blanqueamiento de la raza por medio del mestizaje estuvo también en los discursos de los letrados y políticos mexicanos de este período, que juzgaron positivamente los "altos conocimientos y facultades" que traían los inmigrantes, quienes habrían de servir para imponer la "civilización y la industria" indispensables para el buen desarrollo de la población nacional ${ }^{19}$. Por tanto, las élites políticas brasileña y mexicana, como en buena parte de América Latina, contemplaron la llegada de la inmigración europea como un elemento fundamental en el proceso de construcción nacional. Sin embargo, mientras que el primer país fue capaz de atraer una considerable población de la Europa del sur, el estímulo a la colonización extranjera fue mucho menor en el México porfiriano, pues, aunque las leyes contemplaban subsidios y franquicias para atraer a los colonos y sus familias, como se hizo en Brasil, el Estado no empleó recursos suficientes para hacer efectiva su política de atracción migratoria, de tal manera que México no resultó un destino prioritario $^{20}$.

Los datos censales de la población extranjera residente en Brasil y México revelan cifras significativamente mayores en el primer país (Tablas 1 y 2 ) $^{21}$. La proporción de extranjeros en los censos nacionales mexicanos desde fines del siglo XIX y a lo largo del XX en ningún momento superó el uno por ciento respecto a la población total. Por el contrario, Brasil constituyó uno de los países de destino de la emigración extranjera más importantes del continente americano, después de Argentina y Cuba, de tal modo que en 1920 alcanzaba su máximo del período con un 5,1 por ciento respecto al total de la población registrada en el Recenseamento de ese año.

\footnotetext{
18 SARMIENTO, Érica. Galegos nos trópicos. Invisibilidade e presença da imigração galega no Rio de Janeiro (1880-1930). Porto Alegre: Edipucrs, 2017, pp. 69-70.

19 SALAZAR, Delia. Las cuentas de los sueños. La presencia extranjera en México a través de las estadísticas nacionales, 1880-1914. México: Conaculta, 2010, pp. 70-71.

${ }^{20}$ KUNTZ, Sandra. De las reformas liberales a la gran depresión, 1856-1929. En: KUNTZ, Sandra (coord.). La economía mexicana, 1519-2010. México: El Colegio de México, 2012, pp. 305-353.

${ }^{21}$ Esta es una investigación que se halla todavía en un estadio inicial. Los avances que aquí se muestran son todavía preliminares y hay que señalar de partida las enormes dificultades que existen para poder comparar las comunidades desde el punto de vista cuantitativo, por los límites clásicos de las fuentes censales y la falta de equiparación de otros registros nominales. De modo que se trata por ahora de estimaciones parciales sujetas a una profundización mayor en las fuentes.
} 
Alicia GIL LÁZARO y Érica SARMIENTO DA SILVA. Pautas asistenciales de los inmigrantes españoles en Río de Janeiro y Ciudad de México en perspectiva comparada. Las Sociedades de Beneficencia, siglos XIX y XX.

\begin{tabular}{|l|c|r|r|r|r|r|}
\hline \multicolumn{7}{|c|}{ Población brasileña, extranjera y española en Brasil, 1872-1940 } \\
\hline $\begin{array}{c}\text { Año } \\
\text { censal }\end{array}$ & $\begin{array}{c}\text { Población } \\
\text { Brasileña }\end{array}$ & $\begin{array}{c}\text { Población } \\
\text { extranjera }\end{array}$ & $\begin{array}{c}\text { \% sobre } \\
\text { el total }\end{array}$ & $\begin{array}{c}\text { Población } \\
\text { española }\end{array}$ & $\begin{array}{c}\text { \% sobre } \\
\text { el total }\end{array}$ & $\begin{array}{c}\text { \% sobre } \\
\text { extranjeros }\end{array}$ \\
\hline 1872 & 10112061 & 388459 & 3,8 & --- & --- & --- \\
\hline 1890 & 14333915 & 351545 & 2,5 & --- & -- & --- \\
\hline 1906 & 20569894 & --- & --- & -- & -- & 14,0 \\
\hline 1920 & 30838201 & 1565961 & 5,1 & 219142 & 0,7 & 11,4 \\
\hline 1940 & 41159321 & 1406342 & 3,4 & 160557 & 0,4 & \\
\hline
\end{tabular}

Tabla 1: Población brasileña, extranjera y española en Brasil, 1872-194022 (cifras absolutas y porcentajes). Fuente: Elaboración a partir de los datos censales en Instituto Brasileiro de Geografía e Estatística (IBGE).

\begin{tabular}{|c|c|r|r|r|r|r|}
\hline \multicolumn{7}{|c|}{ Población mexicana, extranjera y española en México, 1895-1930 } \\
\hline $\begin{array}{c}\text { Año } \\
\text { censal }\end{array}$ & $\begin{array}{c}\text { Población } \\
\text { mexicana }\end{array}$ & $\begin{array}{c}\text { Población } \\
\text { extranjera }\end{array}$ & $\begin{array}{c}\text { \% sobre el } \\
\text { total }\end{array}$ & $\begin{array}{c}\text { Población } \\
\text { española }\end{array}$ & $\begin{array}{c}\text { \% sobre el } \\
\text { total }\end{array}$ & $\begin{array}{c}\text { \% sobre } \\
\text { extranjeros }\end{array}$ \\
\hline 1895 & 12577690 & 54737 & 0,43 & 13727 & 0,11 & 25,07 \\
\hline 1900 & 13549080 & 58179 & 0,42 & 16278 & 0,12 & 28,27 \\
\hline 1910 & 15043843 & 116526 & 0,76 & 29541 & 0,20 & 25,35 \\
\hline 1921 & 14226781 & 108076 & 0,75 & 26675 & 0,19 & 24,68 \\
\hline 1930 & 16412135 & 140587 & 0,84 & 28855 & 0,18 & 20,52 \\
\hline
\end{tabular}

Tabla 2: Población mexicana, extranjera y española en México, 1895-1930 (cifras absolutas y porcentajes). Fuente: Elaboración a partir de los datos censales en Instituto Nacional de Estadística, Geografía e Informática (INEGI).

Si dirigimos la atención específicamente a los españoles, su presencia en los censos de Brasil alcanzó un 0,7 por ciento respecto a la población total a la altura de 1920 y un 14 por ciento ese mismo año en relación al conjunto de extranjeros censados. São Paulo fue el principal punto de destino brasileño, al cual los inmigrantes arribaban con el objetivo de trabajar en las estancias cafetaleras del estado y reemplazar a los esclavos liberados ${ }^{23}$. Río ocupó el segundo lugar como destino migratorio, después de la capital paulista. Ciudad de México, por su parte, constituyó el mayor núcleo receptor de inmigrantes peninsulares desde los siglos coloniales y durante la gran emigración, casi la mitad de los llegados al país en $1910^{24}$.

La proporción más alta lograda por los españoles en México fue de un 0,2 por ciento en el censo de 1910, visiblemente inferior a la registrada en Brasil por la misma época. Sin embargo, comparados con las cifras de extranjeros residentes en México, los españoles ocuparon a lo largo del período entre un cuarto y un quinto del total, por delante de estadounidenses y guatemaltecos, que aparecían en segundo y tercer lugar. Se trata de una pauta secular, ya que, si bien el flujo de llegadas de

\footnotetext{
22 Los años censales difieren en los dos países por lo que las comparaciones son solo aproximativas.

${ }^{23}$ KLEIN, Herbert. La inmigración española en Brasil. Gijón: Archivo de Indianos, 1996, p. 88. Según este autor, solo el doce por ciento de todos los españoles que emigraron desde España en la época comprendida entre 1880 y 1930 fueron a Brasil. Argentina entre 1882 y 1930 absorbió el 36 por ciento.

${ }^{24}$ PÉREZ HERRERO, Pedro. Algunas hipótesis de trabajo sobre la inmigración española a México: los comerciantes. En: LIDA, Clara (coord.). Tres aspectos de la presencia española en México durante el Porfiriato. México: El Colegio de México, 1981, pp. 111-112.
} 
españoles a México fue ininterrumpido durante siglos, siempre presentó cifras muy bajas respecto a la población mexicana ${ }^{25}$.

Por tanto, los registros censales, a pesar de los problemas que presentan, muestran que, frente a la población total, los españoles fueron sin duda más numerosos en Brasil, pero, comparados con el resto de las comunidades extranjeras, su presencia en México fue más significativa que la existente en el primer país.

\begin{tabular}{|c|c|r|r|r|r|r|}
\hline \multicolumn{7}{|c|}{ Población brasileña, extranjera y española en Río de Janeiro, 1872-1940 } \\
\hline $\begin{array}{c}\text { Año } \\
\text { censal }\end{array}$ & $\begin{array}{c}\text { Población } \\
\text { de Río }\end{array}$ & $\begin{array}{c}\text { Población } \\
\text { Extranjera }\end{array}$ & $\begin{array}{c}\text { \% sobre } \\
\text { el total }\end{array}$ & $\begin{array}{c}\text { Población } \\
\text { española }\end{array}$ & $\begin{array}{c}\text { \% sobre } \\
\text { población Río }\end{array}$ & $\begin{array}{c}\text { \% sobre } \\
\text { extranjeros }\end{array}$ \\
\hline 1872 & 274972 & 84283 & 30,7 & 1452 & 0,5 & 1,7 \\
\hline 1890 & 522651 & 124352 & 23,8 & 10750 & 2,1 & 8,6 \\
\hline 1906 & 811443 & 210515 & 25,9 & 20699 & 2,6 & 9,8 \\
\hline 1920 & 1167560 & 239129 & 20,5 & 19130 & 1,6 & 8,0 \\
\hline 1940 & 1764467 & 228675 & 13,0 & 12212 & 0,7 & 5,3 \\
\hline
\end{tabular}

Tabla 3: Población brasileña, extranjera y española en Río de Janeiro, 1872-1940 (cifras absolutas y porcentajes). Fuente: Elaboración a partir de los datos censales en Instituto Brasileiro de Geografía e Estatística (IBGE).

¿Qué nos revelan los datos referidos a las dos capitales? Los censos corroboran que la población extranjera constituyó un aporte fundamental en el crecimiento demográfico de Río de Janeiro en el tiempo de la gran oleada migratoria, con un 22,5 de media en el período sobre el total de la población local, aunque su peso sobre el conjunto fue descendiendo hasta la década de 1940 (Tabla 3). De nuevo, las evidencias para la capital mexicana ofrecen una imagen muy distinta a la carioca, con un máximo de 3,7 por ciento frente al total de la población local de la ciudad en el censo de 1910, por lo que no podemos sino reiterar que el principal aporte al crecimiento demográfico de la ciudad provino de la emigración interior frente al claramente exiguo del exterior (Tabla 4).

\begin{tabular}{|r|r|r|r|r|r|r|}
\hline \multicolumn{7}{|c|}{ Población mexicana, extranjera y española en Ciudad de México, 1895-1930 } \\
\hline Año & $\begin{array}{c}\text { Población } \\
\text { mexicana }\end{array}$ & $\begin{array}{r}\text { Población } \\
\text { extranjera }\end{array}$ & $\begin{array}{c}\text { \% sobre } \\
\text { el total }\end{array}$ & $\begin{array}{c}\text { Población } \\
\text { española }\end{array}$ & $\begin{array}{c}\text { \% sobre } \\
\text { mexicanos }\end{array}$ & $\begin{array}{c}\text { \% sobre } \\
\text { extranjeros }\end{array}$ \\
\hline 1895 & 476413 & 9505 & 2,0 & 4300 & 0,9 & 45,2 \\
\hline 1900 & 528277 & 13239 & 2,5 & 6302 & 1,2 & 47,6 \\
\hline 1910 & 694881 & 25872 & 3,7 & 12227 & 1,8 & 47,3 \\
\hline 1921 & 878756 & 27307 & 3,1 & 13533 & 1,5 & 49,6 \\
\hline 1930 & 1192024 & 37552 & 3,2 & 15259 & 1,3 & 40,6 \\
\hline
\end{tabular}

Tabla 4: Población mexicana, extranjera y española en Ciudad de México, 1895-1930 (cifras absolutas y porcentajes). Fuente: Elaboración a partir de los datos censales en Instituto Nacional de Estadística, Geografía e Informática (INEGI).

Paradójicamente, la presencia de españoles comparada con la población local es, por el contrario, similar en las dos ciudades (ligeramente mayor en Río, con un 1,5 por ciento de media frente a un 1,3 en México para todo el período), mientras que lo que difiere expresivamente es el peso de los inmigrantes españoles sobre el

${ }^{25}$ LIDA, Clara. Inmigración... Op. cit., p. 47. 
conjunto de la población extranjera residente en ambas metrópolis. Así, por un lado, los españoles alcanzaron el máximo del período en el censo carioca de 1906 —en torno al diez por ciento respecto al total- manteniendo el tercer lugar dentro del contingente migratorio que se daba en el resto del país, muy por detrás de portugueses e italianos ${ }^{26}$. Los registros de españoles en la capital, por su parte, rozaban casi la mitad de los extranjeros, según el censo de 1910. Esto permite afirmar, en definitiva, que Río y Ciudad de México pueden ser espacios comparables en cuanto a su atracción de población española a lo largo de este período, con cifras relativamente similares respecto a la población local, pero no así en cuanto a su proporción frente a la población foránea.

\subsection{Orígenes geográficos y franjas de edad}

La historiografía de la inmigración en Río de Janeiro ha demostrado que la mayoría de los individuos procedentes de la península ibérica eran hombres (en torno a setenta por ciento), y que frente a la inmigración de carácter familiar propia del estado de São Paulo, a Río llegaron normalmente en solitario y eran solteros ${ }^{27}$. Una gran parte había nacido en Galicia (alrededor del setenta por ciento) y se caracterizaban por ser una comunidad sobre todo urbana y de emigración espontánea ${ }^{28}$. La estructura agraria de esa región norteña española, basada en el minifundio a menudo en régimen de subsistencia, posibilitó que una parte importante de los emigrantes financiase su billete y los gastos de viaje sin depender de la política de pasajes subvencionados que llevó adelante el Estado brasileño con destino a las fazendas cafetaleras paulistas ${ }^{29}$.

Por otro lado, la expansión cafetalera de la provincia de Río se agotó a fines de siglo XIX lo que significó un cambio importante en la economía de la ciudad, así como en el perfil ocupacional de la inmigración que atrajo desde principios de siglo, ya que, frente a São Paulo, los recién llegados se insertaron sobre todo en actividades comerciales y de servicios. Río de Janeiro no fue un mero puerto de acceso al interior rural y agrario del país, sino un objetivo en sí mismo ${ }^{30}$. La presencia española en las ciudades del interior fluminense fue mínima en comparación con el estado paulista.

Érica Sarmiento ha estudiado a los gallegos en Río de Janeiro a partir del cruce de datos de dos fuentes nominativas: por un lado, las matrículas de los afiliados al Hospital Español entre 1859 y 1920; y, por otro, las inscripciones consulares de españoles entre 1877 y 1939 . Sobre el origen geográfico de una muestra de más de

\footnotetext{
26 PASCHOAL GUIMARAES, María L. Espanhóis no Rio de Janeiro (1880-1914). Contribuição à historiografia brasileira [tese de Doutorado]. Universidade do Rio de Janeiro, 1988, p. 7.

27 SARMIENTO, Érica. Galegos nos trópicos... Op. cit., pp. 99-101.

28 PASCHOAL GUIMARAES, María L. Espanhóis no Rio de Janeiro... Op. cit. Entre 1882 y 1914 solo un 7,3 por ciento de los españoles en Rio tenían contrato de trabajo antes de arribar al puerto.

29 VÁZQUEZ, Alexandre. Emigrantes galegos, transportes e remesas (1830-1930). A Coruña: Fundación Barrié, 2015.

30 ZAMORANO, Víctor. De agentes del progreso a elementos del desorden: inmigrantes españoles y exclusión social en Río de Janeiro (1880-1930) [tesis doctoral]. Salamanca: Universidad de Salamanca, 2010, p. 132.
} 
tres mil personas, la autora concluye que las principales provincias de salida de los españoles hacia Río fueron las gallegas y por este orden: Pontevedra, Orense, A Coruña y, a mucha distancia, Lugo (Gráfico 1) ${ }^{31}$. Los registros policiales analizados por Víctor Zamorano muestran una vez más la hegemonía gallega entre los españoles de la ciudad aunque el autor llama la atención de la diversidad de orígenes de la minoría restante: malagueños, granadinos, canarios, barceloneses, aragoneses, navarros, pacenses, madrileños y burgaleses ${ }^{32}$.

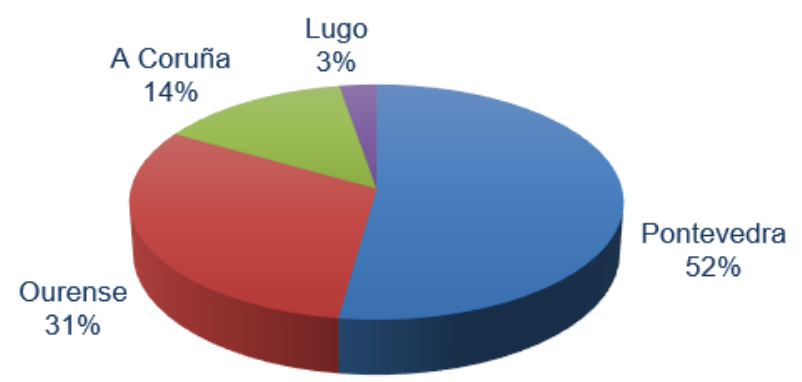

Gráfico 1: Origen geográfico de los inmigrantes gallegos en Río de Janeiro, 1859-1920. Fuente: Sarmiento, Érica. Galegos nos trópicos. Invisibilidade e presença da imigração galega no Rio de Janeiro (1880-1930). Porto Alegre: Edipucrs, 2017, pp. 199-200.

Al igual que Río, Ciudad de México recibió un contingente migratorio español esencialmente masculino —que tendería a disminuir ligeramente en las primeras décadas del siglo $X X-{ }^{33}$.Asimismo, este contingente migratorio se debió a la voluntad individual $y$, en menor medida, a los desplazamientos auspiciados por agentes o compañías de reclutamiento ${ }^{34}$. Pero frente al predominio gallego en la ciudad de Río, la diversificación de orígenes regionales fue característica de la inmigración llegada a Ciudad de México. Los inmigrantes procedían, por lo general, de una periferia poco urbanizada de la península. Los datos recabados por Alicia Gil Lázaro entre los atendidos en la Casa de Salud y Asilo de la Sociedad de Beneficencia Española de México en el período entre 1887 y 1936 permiten afirmar que prácticamente todos ellos eran naturales de la franja cantábrica, el noreste y el noroeste del país y que las dos regiones de origen mayoritarias fueron Asturias y Santander (Gráfico 2) ). $^{35}$

31 SARMIENTO, Érica. Galegos nos trópicos... Op. cit., pp. 91-114. La autora llama la atención del sesgo que puede suponer trabajar con registros que constituyen un acto voluntario para los inmigrantes.

32 ZAMORANO, Víctor. De agentes del progreso... Op. cit., p. 329.

${ }^{33}$ En el Padrón de la Municipalidad de México de 1882 un 85 por cien de los españoles eran varones, pero en el censo de 1930 aproximadamente una de cada cuatro personas de origen español era mujer. JARQUÍN, María T. La población española en la Ciudad de México. En: LIDA, Clara (coord.). Tres aspectos... Op. cit., p. 183.

${ }^{34}$ Las fuentes consulares españolas en México revelan algunos de estos contratos colectivos. Gil Lázaro ha estudiado el caso de las cuadrillas de maestros resineros abulenses contratados por la empresa de íñigo Noriega para explotar los bosques cercanos a la capital mexicana. GIL LÁZARO, Alicia. Inmigración y retorno. Españoles en la Ciudad de México, 1900-1936. Madrid: Marcial Pons, Universidad de Alcalá, 2015, pp. 221-225.

35 Memoria de la Sociedad de Beneficencia Española de 1887, p. 13. A pesar de que en la fuente de información aparezca en algunos casos el nombre de la capital de provincia (Oviedo, por ejemplo), en realidad las memorias capturaban los orígenes provinciales de los asistidos: "[...] $\mathrm{Si}$ a los asistidos en la Casa se les considera por su provincia de origen, suministran el siguiente resultado [...]". 


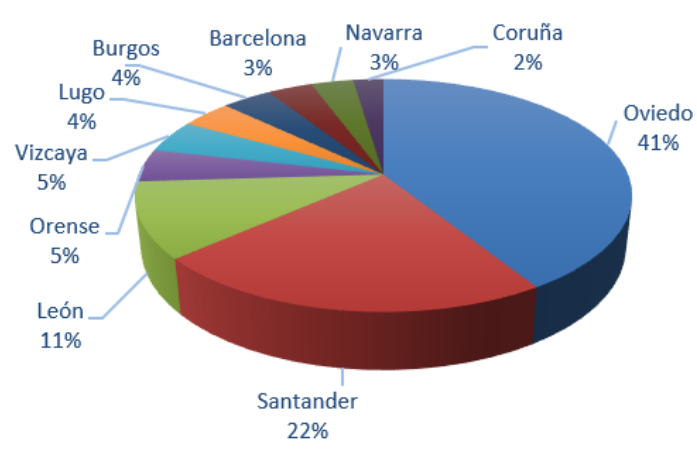

Gráfico 2: Origen geográfico de los españoles en Ciudad de México, 1887-1936. Fuente: Elaborado a partir de las Memorias de la Sociedad de Beneficencia Española de México, años 1887-1936.

La emigración gallega a Río entre 1880 y 1939 estaba constituida por un contingente joven y en edad activa, que comprendía entre los diez y los 39 años. El grueso de llegadas se concentraba entre los catorce y los diecinueve años y entre los treinta y los treinta y cinco años. El predominio de la primera franja sugiere la hipótesis de que entre ellos había una gran parcela en edad de cumplir con los deberes militares y también delatan su soltería. La segunda franja, por el contrario, apunta al perfil del cabeza de familia que emigra en solitario. Los menores de catorce años eran muchos menos en Río que en São Paulo por el escaso peso de la emigración en familia ${ }^{36}$.

De nuevo, la comunidad española radicada en México presentó en líneas generales una estructura etaria bastante similar a la de Río. La edad en el Padrón de 1882 oscilaba entre los quince y los 34 años. Los inmigrantes se concentraban sobre todo en edades adultas y había un porcentaje muy bajo de niños menores de nueve años. La edad promedio era de 28 años. Los datos del Padrón llevan a pensar que los varones posponían el matrimonio hasta obtener una mejor posición económica y solían casarse, por tanto, a una edad tardía. Los casados predominaban en la franja de los 35 a 39 años y en las mujeres a partir de los 25 años $^{37}$. Los datos recabados por Clara Lida para el conjunto del territorio y en el período de mayores llegadas a partir de 1905 demuestran que la mayoría de los españoles entraron al país entre los quince y los 25 años y de nuevo se baraja la hipótesis de la edad militar tanto como la del varón soltero o casado (y con la familia en España) ${ }^{38}$.

\subsection{Ocupaciones}

Los orígenes rurales de los inmigrantes en la península no impidieron que su inserción laboral, tanto en Ciudad de México como en Río de Janeiro, se realizara sobre todo en los sectores secundario y terciario de la economía destinados a satisfacer el mercado interno. El comercio fue la ocupación predominante en los dos

\footnotetext{
${ }^{36}$ SARMIENTO, Érica. Galegos nos trópicos... Op. cit., pp. 100-104.

37 JARQUÍN, María T. La población española... Op. cit., p. 189.

38 LIDA, Clara. Inmigración... Op. cit., pp. 68-70. A partir del estudio del Registro Nacional de Extranjeros, la autora calcula las edades de españoles residentes en todo México, no solo en la capital.
} 
casos, aunque también había una presencia significativa de artesanos y en menor medida de obreros ${ }^{39}$. Las ocupaciones principales no hacían sino reflejar el perfil económico predominante en las dos urbes.

En el Padrón municipal de Ciudad de México de 1882, nueve de cada diez españoles se concentraban en las tareas comerciales. En su gran mayoría se dedicaban a la venta de alimentos y bebidas como mayoristas o minoristas, principalmente en tiendas de "abarrotes" 40 , "estanquillos" y panaderías, y había un número notable de prestamistas ${ }^{41}$. En un porcentaje menor se dedicaban a la explotación agropecuaria, en establos o plantaciones azucareras, y a la producción fabril, centrada en el sector textil. Los artesanos en este registro trabajaban el cuero (zapateros y curtidores) y había también sastres e impresores. En Río, las matriculaciones del Hospital Español entre 1877 y 1939 constatan que un 45 por ciento de las ocupaciones registradas se referían al comercio y la hostelería.

Los registros consulares cariocas presentan, además, un número elevado de jornaleros, trabajadores no cualificados e informales que, en principio, no parece asemejarse al perfil de la inmigración en Ciudad de México ${ }^{42}$. Según Sarmiento un jornalero:

"[...] podia ser qualquer operário não qualificado ou simplesmente um empregado novo e sem qualificação do setor terciário. Os jovens emigrantes recém-chegados que ainda não estavam estabelecidos no mercado de trabalho e que não tinham nenhuma especialização podiam ser considerados jornaleiros" ${ }^{\prime 3}$.

Oficios comunes entre los españoles de Río fueron los cocineros, panaderos, albañiles, carpinteros, zapateros, marineros, camareros y conductores, así como trabajadores domésticos.

Por otro lado, uno de los rasgos definidores del sistema migratorio español en diferentes latitudes fue su especialización productiva, fuertemente influida por el lugar de origen. En la capital mexicana, vascos y catalanes mostraron una tendencia a las actividades industriales, en respuesta al mayor grado de industrialización de las áreas de las que provenían; existía, asimismo, una asociación de los negocios de

\footnotetext{
39 PÉREZ HERRERO, Pedro. Algunas hipótesis... Op. cit., p. 124. El autor llama la atención sobre la imprecisión del término de 'comercio', puesto que podía referirse tanto a la propiedad de un gran almacén como de un pequeño abarrote, a un empresario o a un dependiente. Sarmiento corrobora esta idea "[...] quando a profissão aparece como 'do comércio', não há a certeza de que esses galegos eram os proprietários do comercio ou se eram empregados". SARMIENTO, Érica. Galegos dos trópicos... Op. cit., p. 152.

40 JARQUÍN, María T. La población española... Op. cit., p. 190. Los abarrotes eran pequeñas tiendas de alimentación, aunque a menudo ofrecían toda clase de productos.

${ }^{41}$ GIL LÁZARO, Alicia. Inmigración y retorno... Op. cit., pp. 141-142. En 1913 el grueso de las casas de préstamos estaba en manos españolas según el consulado. Estos se unieron durante la Revolución en una Unión de Casas de Préstamos al que pertenecían, según esta autora, un total de 98 inmigrantes.

42 Las fichas del Registro Nacional de Extranjeros trabajadas por Lida muestran un 16,2 por ciento de "trabajo no especializado o no especificado, donde la autora supone que había un predominio del trabajo doméstico no remunerado y de los servicios, pero no se debe excluir tampoco esta categoría de jornaleros, tal y como Sarmiento la define. LIDA, Clara. Inmigración... Op. cit., pp. 60-61.

${ }^{43}$ SARMIENTO, Érica. Galegos nos trópicos... Op. cit., p. 156.
} 
asturianos con el crédito; las actividades agropecuarias con los cántabros; los gallegos, finalmente, se dedicaban sobre todo a la hostelería, lo que incluía la propiedad o el empleo en hoteles, fondas y restaurantes. Entre los gallegos de Río fue también común la especialización en este sector. Ya fuera como empresarios o asalariados, un porcentaje importante de los registros capturados por Sarmiento muestra el trabajo gallego en pequeños botequins, casas de comidas, restaurantes y, sobre todo, varias formas del negocio del hospedaje, desde hoteles a pensiones baratas. El popular barrio de San Antonio, en la localidad de Lapa, especializado en las actividades de ocio y diversión, estaba poblado por numerosas pequeñas y medianas empresas de gallegos tales como bares, cafés, cabarés, casas de juego y las famosas estalagens o posadas de reducido tamaño y dudosa reputación, así como burdeles ${ }^{44}$.

La división por género depara nuevamente similitudes entre los dos grupos. Los registros sobre las emigrantes a México muestran que muchas mujeres llegaban bajo la tutela de una familia para servir como asistentas 0 al cuidado de menores 0 ancianos. Los partes policiales capitalinos referidos a extranjeros reportan denuncias contra mujeres españolas que ejercían la prostitución ${ }^{45}$. Lo más normal era que las mujeres casadas se dedicaran a las labores del hogar o trabajaran en los negocios familiares. Un perfil muy similar en la ocupación de las mujeres se dio en Río de Janeiro, al que habría que añadir los oficios de lavanderas por encargo y la costura, a menudo en pequeños talleres 0 en sus casas. Las mujeres solteras podían aparecer también en algún empleo fabril, sobre todo en la industria textil ${ }^{46}$.

Javier Moreno ha estudiado una serie de inventarios de los bienes y derechos de las empresas españolas asentadas en Ciudad de México entre 1913 y 1914, levantados a instancias de las autoridades diplomáticas, cruzando los datos extraídos con otras fuentes primarias como cédulas personales, pasaportes o registros consulares. A partir de esta documentación, el autor halla que un 16,3 por ciento de la población masculina adulta de origen español eran comerciantes y un 79,9 por ciento asalariados no cualificados. El porcentaje restante lo formaban profesionales, funcionarios y religiosos. El crecimiento del flujo migratorio en los años previos al conflicto civil pudo haber cambiado el perfil socio económico anterior, debido a la llegada de muchos jóvenes dependientes, empleados y, en menor medida, jornaleros, como "motores de sangre" que, al momento de levantarse dichos registros aún no habían podido establecerse por cuenta propia. Además, el autor localiza en la capital las actividades económicas de seiscientos empresarios que corroboran la idea tradicional del dinamismo inversor empresarial de los españoles: dos docenas de pequeñas haciendas, grandes explotaciones ganaderas en las salidas de la ciudad, un número notable de industrias, esencialmente textileras y alimentarias, pero también papeleras, cigarreras y otras. Uno de cada tres empresarios de esta muestra, sin embargo, se dedicaba al negocio de los

\footnotetext{
${ }^{44}$ NUNES AZEVEDO, André y SARMIENTO, Érica. Las 'parroquias' en la ciudad de Rio... Op. cit.

45 GIL LÁZARO, Alicia. Extranjeros perniciosos... Op. cit., pp. 490-491.

46 SARMIENTO, Érica. Galegos nos trópicos... Op. cit., pp. 164-165 LIDA, Clara. Inmigración... Op. cit., pp. 50-51.
} 
abarrotes ${ }^{47}$. En el mismo sentido, el Directorio de la colonia española editado en Ciudad de México en 1937 incluía más de seiscientos negocios de abarrotes, el sector más abundante de este registro ${ }^{48}$.

\subsection{Pautas asociativas}

La creación de asociaciones no es, en principio, sino una expresión más de las redes de solidaridad étnica trazadas en torno a los lazos familiares y vecinales que canalizaron el viaje y la instalación inicial, y que explica también otros fenómenos como la reunión de los naturales de una comarca en un mismo barrio o gremio, gracias a la formación de cadenas migratorias. Como expresión formal de la solidaridad entre pares, las asociaciones adoptaron distintas fórmulas y objetivos, aunque todas ellas perseguían hacer viables los proyectos migratorios y, en este sentido, fuera cual fuera su naturaleza, las funciones asistenciales cumplieron un papel apreciable en el tiempo de la gran oleada migratoria. Algunas se crearon exclusivamente con tal finalidad mientras que otras la ejercerían de manera puntual y selectiva, pues se trataba de uno entre otros muchos objetivos.

Las similitudes y diferencias que se han analizado en cuanto al perfil y el tamaño de las dos comunidades migratorias son importantes a la hora de comparar sus prácticas asociativas. Río de Janeiro acogió, como se ha visto, a una colonia española muy compacta desde el punto de vista del origen geográfico. La inserción de los gallegos en una urbe melting-pot de una gran diversidad racial y cultural pudo haber condicionado sus fórmulas asociativas, las cuales, en aras de una mayor cohesión, tuvieron en inicio un carácter mucho más nacional y regional que microterritorial. El colectivo español en la capital mexicana, más diverso en sus orígenes geográficos que el de Río, pero diminuto frente al aluvión de inmigrantes del interior del país que poblaron la gran ciudad por el mismo tiempo en que ellos llegaron, desarrolló también la vía nacional en la gestación de sus instituciones a lo largo del siglo XIX, mientras que la opción regional no llegaría sino ya a comienzos del $\mathrm{XX}$, en respuesta a las propias dinámicas internas de un grupo en crecimiento, según Alicia Gil Lázaro.

A pesar de este perfil mayoritario, en Río se sabe de la existencia de varias formaciones de parroquia y municipio definidas por su interés prioritario en la beneficencia en el lugar de origen. Entre ellas, Sarmiento cita la asociación Aurora del Porvenir, fundada en 1912 por inmigrantes del Concejo de Tomiño (Pontevedra) y registrada con la intención de fundar una escuela en su municipio ${ }^{49}$. En Ciudad de México, al contrario que en Río, no hay constancia de que se fundaran sociedades

47 MORENO, Javier. La otra España. Empresas y empresarios españoles en la ciudad de México durante la Revolución. América Latina en la Historia Económica. 2007, n. 27, pp. 117-118.

48 VILLAR, F. Directorio de la colonia española. México: s.n., 1937. Le seguían a mucha distancia las panaderías (164 establecimientos) y la venta de ropa (137). El ramo de la hostelería sumaba en total 143 negocios que incluían cantinas, restaurantes, cafés, cabarés y cervecerías.

49 SARMIENTO, Érica. Galegos nos trópicos... Op. cit., pp. 63-64 y 112. No fue la única. Al menos siete más aparecen citadas en el Boletín del Consejo Superior de Emigración y otras tres en el Arquivo da Emigración, pero no se ha encontrado documentación sobre ellas. La aparente escasez o inexistencia de estas sociedades microterritoriales en Río, abundantes como son en otros destinos migratorios del cono sur, constituye una incógnita para la investigación sobre la presencia española en la capital brasileña. 
microterritoriales, tal vez porque estas se hallaban muy apegadas al ámbito gallego y la presencia de estos entre los inmigrantes españoles en la ciudad fue más reducida ${ }^{50}$.

La preferencia por las asociaciones de carácter nacional y regional podría explicarse en principio como una estrategia orientada a lograr una mayor afiliación y, con ello, el sostenimiento económico inicial de las entidades. Como afirma José Moya, un número no muy elevado de individuos de una nacionalidad podía determinar que se optara por fundar organismos que permitiesen incluirlos a todos, sin discriminar por su origen regional o provincial ${ }^{51}$. Este parece que fue el caso tanto en Rio como en Ciudad de México. Las instituciones pioneras de los españoles en ambas ciudades fueron precisamente las de carácter benéfico-asistencial, la Sociedad de Beneficencia Española de México, fundada en 1842, y su homóloga en Rio, que con el mismo nombre y naturaleza fue creada diecisiete años después.

Ese supuesto afán integrador habría influido también en la creación del elitista Casino Español de México en $1863^{52}$, y, en una fecha mucho más tardía, 1899, el Centro Galego de Río ${ }^{53}$. Estas entidades cumplían funciones recreativas y culturales, ante todo, pero se unía también, en primer término, un afán político y social de las élites de representación de la colonia ante la sociedad receptora y la de origen y también frente a las autoridades políticas locales y las diplomáticas. Según Sarmiento, el Centro Gallego fue en realidad una prolongación de la Beneficencia Española, por más que funcionaran como órganos independientes. Su creación se explicaría por el propio crecimiento del colectivo gallego, su ansia de visibilidad y la necesidad de ir más allá de la acción asistencial, mostrando una imagen más intelectual del grupo ${ }^{54}$.

En general los cuerpos directivos de estas asociaciones remitían a un perfil de hombres de negocios con una proyección socioeconómica ya consolidada, con varias décadas de estancia en el país y representatividad en sus comunidades. Así, tanto en Ciudad de México como en Río, los fundadores y dirigentes de los centros ya eran socios distinguidos en las Sociedades de Beneficencia y habían ocupado cargos importantes en esas dos instituciones ${ }^{55}$. Los líderes étnicos no solo poseían una sólida situación económica y carisma personal, sino que este venía dado por una mayor experiencia profesional, asociativa, política o periodística en el país de origen $\mathrm{o}$ en el de destino, por lo que eran "susceptibles de aportar recursos

\footnotetext{
50 NÚÑEZ SEIXAS, Xosé M. Las patrias ausentes... Op. cit., pp. 335-360.

51 MOYA, José C. Los inmigrantes y sus asociaciones: una perspectiva histórica global. Apuntes de investigación del CECYP. 2008, n. 13, p. 11.

52 Sin embargo, la trayectoria del primero estuvo marcada más bien por un talante particularmente elitista que acabó disolviendo cualquier intencionalidad de inclusión que pudiera haber tenido en sus inicios el apellido 'español', convirtiéndolo en un selecto club de notables de la colonia. Tuvo sus propios órganos de prensa y fungió en diferentes momentos como representación de facto de los españoles de México. Véase GUTIÉRREZ, Adriana. El Casino Español de México. 140 años de historia. México: Editorial Porrúa, 2004.

53 SARMIENTO, Érica. Galegos nos trópicos... Op. cit., p. 473.

54 Ibídem, pp. 478-479.

55 Ibídem, p. 473; GIL LÁZARO, Alicia. Inmigración y retorno... Op. cit., pp. 133-135.
} 
inmateriales a las empresas colectivas" 56 .

Por otro lado, las tensiones dentro de estas asociaciones fueron habituales y están bien documentadas en los dos casos; lejos de resultar algo excepcional, tales tensiones se reprodujeron en las distintas latitudes donde se asentaban poblaciones españolas expatriadas y organizadas, en tanto las asociaciones constituyeron la vía de entrada tanto para la participación política de los inmigrantes -a través de la creación de liderazgos fuertes en su seno- como para el ascenso social en la sociedad receptora y en la de origen. No es de extrañar que se produjeran constantes desencuentros tanto al interior de los propios organismos como entre unos y otros.

De hecho, una fricción generacional, a principios del siglo $\mathrm{XX}$, coincidente con el mayor aumento del flujo migratorio desde España, fue lo que provocó que comenzaran a surgir nuevas iniciativas asociativas en Ciudad de México. Estas adoptaron un carácter regional —en algunos casos nacionalista, como el vasco y catalán-y fueron impulsadas por una generación más joven en la que despuntaban los asturianos, catalanes, santanderinos, vascos y gallegos que habían llegado a fines de siglo y se hallaban en medio de su proceso de ascenso económico, por lo que también tuvo un tono de conflicto de clase. Estas nuevas generaciones pugnaban por una participación mayor en la dirección comunitaria y por conformar nuevos liderazgos fuera del exclusivo ámbito del Casino ${ }^{57}$. Fruto de esta misma reacción más inclusiva, se creó en 1900 un Centro de Dependientes, pluriclasista y corporativo, cuyos objetivos serían esencialmente recreativos y sociales, aunque no excluirían la asistencia sanitaria ${ }^{58}$.

En Río, por la misma época, el asociacionismo liderado por una Sociedad de Beneficencia de perfil geográfico tradicionalmente gallego se enfrentaba a una disminución de la afiliación y una pérdida del interés por la actividad colectiva. Para muchos de ellos simplemente no era posible pagar las cuotas. En 1900 surgió el Centro Gallego de una escisión del Casino Español, que ya existía desde una década atrás y que aglutinaba a la comunidad catalana residente en la ciudad. En el Centro Gallego las tensiones se derivaron desde los primeros tiempos de la actividad política de carácter anarquista de algunos de los miembros, pugnas que se prolongaron a lo largo de la existencia de este organismo, hasta su cierre a principios de los años cuarenta ${ }^{59}$. Finalmente, en 1927 nació el Centro Español de Río de nuevo bajo la iniciativa de la Beneficencia, con un perfil recreativo y cultural similar al gallego, y con el objetivo de "estrechar las relaciones de afecto entre los

\footnotetext{
${ }^{56}$ NÚÑEZ SEIXAS, Xosé M. Las patrias ausentes... Op. cit., pp. 123-124.

57 GIL LÁZARO, Alicia. Inmigración y retorno... Op. cit., pp. 137-144. La coyuntura revolucionaria dificultó la consolidación de estos centros, que no alcanzaron cierta estabilidad hasta la década siguiente y en algunos casos aún después.

58 GUTIÉRREZ, Mar. La nación española and the Centro de Dependientes: the silenced projects of the Spanish colony in the city of México (1900-1901). En: NAVARRO AZCUE, Concepción y PRADO, Gustavo H. (coords.). Intellectualism and migration: international networks of European culture in America (19th-21st). 2016, pp. 195-216. Según esta autora, el Centro terminó siendo cooptado por personajes cercanos al Casino Español. Véase también GUTIÉRREZ, Mar. Salud, beneficencia y mutualismo: la colonia española en la ciudad de México durante el Porfiriato. História, Ciéncias, Saúde - Manguinhos. 2021, v. 28, n. 2, pp. 437-454.
}

59 SARMIENTO, Érica. Galegos nos trópicos... Op. cit., pp. 473-498. 
españoles, fomentar su convivencia y procurar que entre ellos exista la más cordial inteligencia". Claramente, se trataba de una reacción a décadas de rivalidades, escasa participación e innumerables conflictos que afectaron al movimiento asociativo español de Río60.

A través de un asociacionismo organizado y sólido, las élites de las dos ciudades anhelaban dar una mayor visibilidad al colectivo y neutralizar las imágenes estereotipadas de los inmigrantes que circulaban por entonces, algo que se tornaría difícil en las diferentes coyunturas políticas autóctonas, como la Revolución mexicana o, posteriormente, el Brasil de Getulio Vargas ${ }^{61}$.

\section{Las Sociedades de Beneficencia}

Como se ha dicho, el asociacionismo asistencial constituyó una de las facetas más importantes de la acción integradora de los inmigrantes en los países de destino, en tanto el cuidado de su salud y la asistencia a los que la necesitaban fueron fenómenos consustanciales al hecho migratorio que, en la mayoría de los casos, ni las instituciones tradicionales (como los grupos de parentesco) o las modernas (como el Estado o las corporaciones) eran capaces de satisfacer ${ }^{62}$. Las primeras asociaciones creadas por inmigrantes españoles en el continente americano en el siglo XIX fueron las de carácter asistencial, siendo los dos modelos más extendidos las Sociedades de Beneficencia y las Sociedades de Socorros Mutuos. Ninguno de estos modelos fue inventado por los inmigrantes en sus lugares de destino, sino que eran bien conocidos en el viejo mundo antes de que comenzara el éxodo europeo masivo hacia América.

Las primeras se fundaron a partir de un esquema tradicional de raíz cristiana heredado del Antiguo Régimen, que en la América Latina colonial se había canalizado a través de las cofradías de naturales ${ }^{63}$. Estas fueron desapareciendo tras ser prohibidas durante el proceso independentista, pero a partir de la década de 1840 , las sociedades benéficas de los inmigrantes recuperaron un discurso muy similar al de las extintas congregaciones en cuanto al funcionamiento interno de los organismos. Inicialmente su financiación descansaba en el ejercicio de la caridad hacia los inmigrantes pobres por parte de unos socios protectores o benefactores que hacían donaciones regulares de dinero o productos para hospitales o asilos. De este modo, las sociedades benéficas incorporaban un mecanismo paternalista que impuso una estructura muy jerárquica en su interior y depositó la dirección en manos

\footnotetext{
60 lbídem.

61 lbídem, pp. 462-463.

62 MOYA, José C. Los inmigrantes y sus asociaciones... Op. cit., p. 11.

63 Las congregaciones de naturales reunían a los oriundos de determinadas regiones peninsulares en torno a devociones metropolitanas. Las primeras fueron las vasco-navarras, con presencia en Perú y Potosí, desde el último cuarto del siglo XVI. En 1612 se fundó de forma oficial en Lima la Cofradía de la Virgen de Aranzazu, gracias al predominio vasco en el comercio de la capital del virreinato. Los estatutos de esta hermandad fueron copiados y reproducidos por otras similares en México, Santiago de Chile y otras ciudades americanas. GARCíA, Clara. Sociedad, crédito y cofradía en Nueva España a fines de la época colonial: el caso de Nuestra Señora de Aranzazu. Historias. 1983, pp. 53-68.
} 
externas a los asistidos, las de las élites de las comunidades migratorias ${ }^{64}$.

Frente al perfil pluriclasista de las beneficencias, las sociedades mutuales de los inmigrantes fueron concebidas a partir de los lineamientos solidarios decimonónicos de las friendly societies anglosajonas. Como se sabe, las Sociedades de Socorros Mutuos se convirtieron en el modelo dominante de organización asistencial del movimiento obrero europeo a mitad de siglo y serían también la fórmula más extendida y duradera entre los trabajadores españoles. En el último tercio del siglo XIX, pasaron a ser también las asociaciones más usuales de los emigrantes europeos en los destinos americanos. Su base doctrinal imponía idealmente el igualitarismo entre los miembros, de tal forma que todos debían colaborar a su sostenimiento a través del pago de una cuota regular como contrapartida por los servicios prestados por la asociación, que sería gestionada además por los propios afiliados $^{65}$.

En el contexto migratorio, ambas modalidades ofrecían una variedad similar de servicios asistenciales, que en algunos casos alcanzó una dimensión tal que, se decía, iba "desde la cuna hasta la tumba": asistencia en los nacimientos, cuidado médico y hospitalario, remedios, seguro de desempleo y discapacidad, repatriación gratuita o admisión en asilos de ancianos o huérfanos en caso de indigencia, servicios de sepelio y aun una fosa o nicho para ser enterrados entre otros paisanos. Como afirma José Moya, el rango de los servicios dependía, por supuesto, del tamaño, número de miembros y riqueza de la institución ${ }^{66}$. A partir de estos dos modelos esquemáticos una variedad de fórmulas asistenciales y distintas soluciones de gestión y financiación surgiría durante la oleada migratoria, en muchos casos como una combinación de diferentes aspectos de los dos primeros.

El crecimiento de las comunidades migratorias y de sus necesidades asistenciales ponía en peligro la estabilidad de instituciones benéficas sostenidas únicamente en la caridad y muchas de ellas organizaron pronto sus finanzas sobre la base mutual de la afiliación obligatoria y el pago regular de cuotas. Con este cambio, las prestaciones puramente benéficas pasarían necesariamente a ser mínimas y el monto de las donaciones devino en un porcentaje a menudo marginal de los ingresos ${ }^{67}$. Bajo este esquema las beneficencias se expandieron prácticamente por todos los países del continente americano, desde mediados del siglo XIX y a lo largo de la primera mitad del XX. México, Brasil y Argentina fueron los destinos migratorios con mayor número de asociaciones de este tipo, mientras que, en Cuba, territorio español hasta 1898, se desarrolló un modelo singular de base regional.

\footnotetext{
64 FERNÁNDEZ, Alejandro. El asociacionismo español en Argentina... Op. cit., p. 211.

65 WEINBREN, Daniel. Supporting Self-Help, Charity, Mutuality and Reciprocity in Nineteeth-Century Britain. En: HARRIS, Bernard y BRIDGEN, Paul (coords.). Charity and Mutual Aid in Europe and North America since 1800. New York: Routledge, 2007, pp. 67-88.

${ }^{66}$ MOYA, José C. Los inmigrantes y sus asociaciones... Op. cit., p. 24.

${ }^{67}$ GIL LÁZARO, Alicia. Inmigración y retorno... Op. cit., pp.
} 


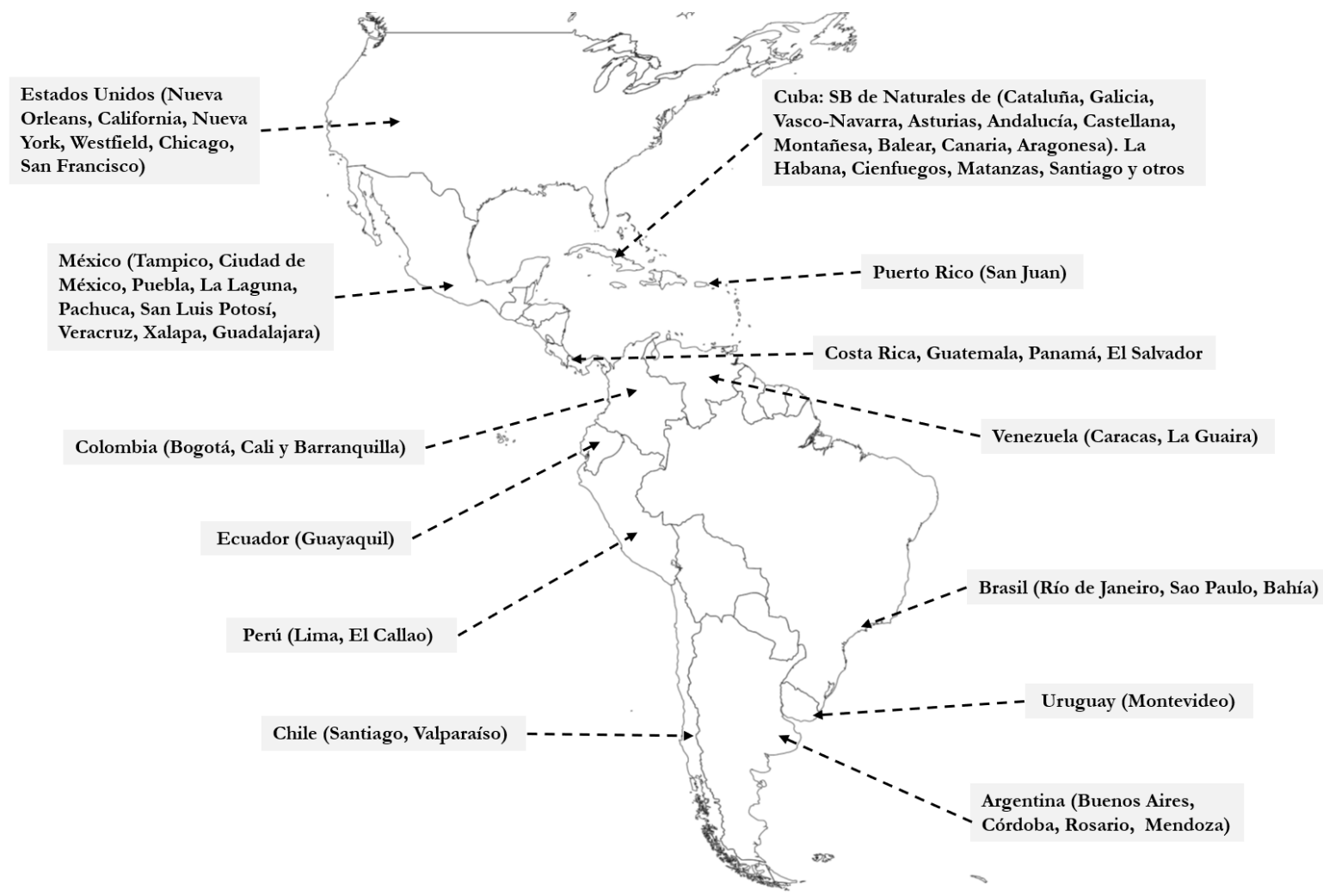

Mapa 1: Sociedades de Beneficencia Española en América Latina (siglos XIX y XX). Fuente: Elaboración propia.

Su funcionamiento interno se hizo mutualista - muchas nacieron ya con élpero su discurso oficial siguió anclado en el ejercicio de la caridad y la reafirmación de su jerarquización interna, de tal modo que su administración y dirección se mantuvo en manos de una burguesía adinerada de las colectividades que encontró en estas asociaciones un camino para el ascenso político y la visibilidad social ${ }^{68}$.

El primer establecimiento de este tipo en América se fundó en Tampico, uno de los puertos atlánticos más importantes de México, en la temprana fecha de 1840, bajo la iniciativa del primer cónsul general de España en México tras la independencia, Francisco Preto y Neto. Dos años después, en 1842, el mismo diplomático alentó entre la élite de la colonia hispana de la capital de México la creación de una institución similar a la tampiqueña, denominada Sociedad de Beneficencia Española de México.

A mediados de siglo, este mismo proceso alentado desde instancias diplomáticas y grupos de españoles activos en el comercio y las finanzas se estaba dando simultáneamente en otras latitudes americanas. Así, en Cuba, la primera

68 FERNANDEZ, Alejandro. El asociacionismo español en el cono sur de América: una visión comparativa. En: BLANCO, Juan A. y DACOSTA, Arsenio (eds.). El asociacionismo... Op. cit., p. 216. La modalidad benéfica se extendió en el cono sur sobre todo en lugares donde la inmigración española no era tan abundante y la diversificación económica y social de las comunidades era menor. Frente a los grandes centros de recepción como São Paulo o Buenos Aires, las colonias españolas de Ciudad de México o Río eran mucho más pequeñas y menos diversificadas socialmente. 
Sociedad de Beneficencia de Naturales la organizaron los ricos comerciantes catalanes residentes en La Habana en 1841, mientras que once años más tarde, en 1852, se creaba la Sociedad Española de Beneficencia de Buenos Aires. También en Brasil encontramos instituciones benéficas en fechas tempranas: la primera se fundó en Río de Janeiro en 1859 y otras más le seguirían en las décadas siguientes.

No deja de llamar la atención el hecho de que estas fundaciones tuvieran lugar en un tiempo tan alejado aun del inicio de la oleada masiva de emigración exterior española, que, como sabemos, no se produjo hasta la década de 1880 , momento a partir del cual se fue conformando la mayor parte del tejido asociativo de la emigración española. En las antiguas posesiones españolas del continente la explicación reside en la permanencia de focos de población española de diversa entidad que, tras la tormenta revolucionaria y la disolución del imperio, recompusieron sus formas de vida tradicionales y reanudaron antiguas cadenas migratorias, en un flujo todavía pequeño pero continuo que habría de atravesar el siglo y que ha sido muy bien estudiado por la historiografía de las migraciones tempranas ${ }^{69}$.

Sin embargo, frente a esa continuidad en términos demográficos y económicos de las comunidades españolas de los antiguos virreinatos a las naciones independientes, en el Brasil imperial, tras la independencia, el contingente migratorio más importante fue sin duda el portugués, establecido en el país mucho antes que cualquier otro grupo extranjero y sobre el que recaían prejuicios de larga duración entre las poblaciones locales, por un lado como antiguos colonizadores y explotadores, y, por otro, como trabajadores en los estratos más bajos de la sociedad, brutos e ignorantes ${ }^{70}$.

Como ya se ha dicho, la corriente migratoria española que se dirigió a Brasil a lo largo del siglo XIX fue protagonizada por gallegos, que recalaron en gran medida en las principales ciudades como Río de Janeiro, São Paulo, Santos, Salvador de Bahía y Porto Alegre. En muchos casos, estas comunidades galaicas se 'fundieron' con los inmigrantes portugueses debido a las similitudes en su perfil laboral, sus orígenes campesinos, escasa cualificación y afinidad lingüística y cultural. Efectivamente, a ojos de la sociedad carioca, gallego y portugués tendieron a ser términos intercambiables, de tal manera que a menudo el gentilicio 'gallego' se usaba para referirse a los inmigrantes lusitanos o al revés atribuyéndoles similares prejuicios a ambos, como los antes citados. Esto terminó provocando, según Érica Sarmiento, una invisibilización de los gallegos en la sociedad de Río de Janeiro, justamente por el proceso de asimilación al que se sometió a los dos grupos. Solo si tenemos en cuenta este hecho, se explica la temprana conformación de una comunidad "suficientemente numerosa para formar as suas associaçðes", en palabras de esta autora ${ }^{71}$.

\footnotetext{
69 Véase YÁÑEZ, César. Saltar con red. La temprana emigración catalana a América, ca. 1830-1870. Madrid: Alianza, 1996; DE CRISTÓFORIS, Nadia. Bajo la cruz del sur: gallegos y asturianos en Buenos Aires (1820-1870). Coruña: Fundación Pedro Barrié de la Maza, 2010.

70 SARMIENTO, Érica. Galegos nos trópicos... Op. cit., pp. 75-91.

71 Ibídem, p. 459. Eso lleva a pensar, incluso, en una infrarrepresentación de los gallegos en los censos. Sarmiento afirma que entre un setenta y un noventa por ciento de los españoles de Río eran gallegos.
} 
La existencia de una sociedad benéfica de españoles en Río en un momento tan temprano como 1859, por tanto, solo se entiende desde la precocidad con la que se conformó esta corriente migratoria de gallegos y su desarrollo singular frente al resto del continente, en un camino paralelo al que siguió la emigración portuguesa. El sur de Galicia y el norte portugués conformaban entonces una frontera porosa y culturalmente muy próxima. Según Alexandre Vázquez, una parte significativa de las salidas al exterior de los gallegos se efectuaba por puertos portugueses y a destinos tradicionales de estos ${ }^{72}$.

De igual modo, hay que tener en cuenta que, frente a ese estereotipo del gallego pobre y bruto, un segmento de la comunidad creció económicamente. Solo la fortaleza temprana de un conjunto de inmigrantes bien establecidos habría podido alentar la creación de la institución benéfica, siempre siguiendo de cerca los modelos asociativos lusitanos, sobre todo el de la Real y Benemérita Sociedad de Beneficencia Portuguesa creada en $1840^{73}$. La pugna social por hacerse visibles, limpiar la imagen negativa que se tenía de ellos, dignificar su quehacer y su nacionalidad frente a la sociedad carioca y distinguirse de los portugueses fueron factores importantes en el nacimiento y expansión institucional de la Beneficencia impulsada por los gallegos ${ }^{74}$.

Desde esta perspectiva se puede pensar que la benéfica española de Río, frente a la de Tampico o Ciudad de México - que pasan por ser las primeras fundaciones de este tipo en América- mostró un espíritu más pionero y precoz que ninguna otra de las españolas, en el sentido de que su base no respondía a un pasado en común, a una corriente antigua, o a una tradición secular reanudada tras un tiempo de conflictos; un flujo 'invisible' a la mirada exterior la había hecho posible.

Por otro lado, la fundación benéfica española de Ciudad de México, al igual que la de Tampico o el resto de las creadas en este país se debieron, como vimos, a un impulso oficial propiciado por las autoridades diplomáticas $y$, en definitiva, a directrices provenientes de la península. Fue el primer paso tras el reconocimiento español de la independencia mexicana en 1838 hacia una normalización de relaciones, establecer contacto con las poblaciones españolas allí asentadas y colaborar en la organización de su tejido societario. Además, desde su constitución misma, los organismos estuvieron estrechamente relacionados con las autoridades -locales y diplomáticas - lo cual acentuó su sentido identitario nacional. Tras la fundación capitalina vendría la de Pachuca en 1843 y veinte años después, cuando empezaba ya a aumentar la afluencia de inmigrantes al país, se crearon otros dos organismos, en Puebla primero (1860) y en Veracruz después (1869), en el contexto

\footnotetext{
72 VÁZQUEZ, Alexandre. Emigrantes galegos... Op.cit., pp. 340-345. Era una pauta habitual de los gallegos emigrar por puertos portugueses.

${ }^{73}$ PORTO, Ángela [et al.]. (orgs.). Historia de la salud de Río de Janeiro. Instituciones y patrimonio arquitectónico (1808-1958). Rio de Janeiro: Fiocruz, 2008.

74 Frente a esto, la historiografía mexicana ha resaltado la intensa visibilidad de la comunidad española en la capital mexicana (y en el interior del país), no por su tamaño, como hemos visto, sino por su actividad económica, su cercanía al poder político y su pasado colonizador. El paralelismo en este caso podría trazarse, grosso modo, con la colonia portuguesa, especialmente en cuanto a la pervivencia de enraizados prejuicios en la sociedad local frente a este grupo migratorio.
} 
del crecimiento industrial del eje Veracruz-Puebla-Ciudad de México, en el que los empresarios españoles alcanzaron un marcado protagonismo ${ }^{75}$. En un lapso de setenta años, desde 1840 y hasta 1916, se erigieron al menos once beneficencias españolas en México.

Como decimos, desde un principio, las asociaciones incorporaron funciones de representación de los intereses del colectivo inmigrante ante las autoridades de los países de acogida y/o ante el Estado español y sus delegaciones consulares y diplomáticas. Así, los estatutos de la sociedad de Ciudad de México concedían el trato de socios honorarios a los ministros de la Legación y cónsules. El art. 5ํ del reglamento de la Beneficencia capitalina de 1842 nombraba "protector nato" al ministro de España en México, con la facultad de presidir las reuniones a las que asistiera $^{76}$.

Sin embargo, esta cercanía al poder político no parece que se diera en igual medida la Sociedad establecida en Río. Sarmiento llama la atención sobre la ausencia usual de alusiones a las instituciones oficiales en sus documentos programáticos 0 en las memorias anuales "jamais mencionando, entre os agradecimientos e homenagens, alguma instituição oficial, como, por exemplo, o Consulado Espanhol do Río de Janeiro [...]"77.si bien no se puede descartar que en su fundación interviniera la autoridad consular, el distanciamiento posterior pudo ser una realidad plausible.

Para los dirigentes de la Sociedad, en un contexto en el que el Estado español no ejercía protección alguna sobre sus súbditos emigrados, su misión principal era asegurar el apoyo y el amparo de la comunidad española y de aquellos emigrantes que no disponían de condiciones económicas para recibir una atención sanitaria. En el discurso institucional se percibe la necesidad de marcar las distancias respecto a las autoridades consulares y la independencia de los organismos respecto al gobierno de España ${ }^{78}$. Las quejas por el abandono al que sometieron los distintos gobiernos españoles a sus expatriados fueron constantes y se sucedieron en el tiempo entre estos organismos en Brasil, algo que contrasta bastante con la cercanía al poder que lucirían las beneficencias en México.

El éxito de estas sociedades dependió en todo momento de su habilidad para atraer y conservar el mayor número posible de afiliados. Apenas tenemos datos de afiliación de la Sociedad de Río. Elda González afirma que, en el momento de erección del hospital, en 1928, debía haber unos dos mil quinientos afiliados a la Sociedad Española de Beneficencia ${ }^{79}$. Mientras, los números de afiliación que presentan las Memorias anuales de la Sociedad benéfica de Ciudad de México a la altura de 1930, estudiadas por Gil Lázaro, suponían el triple de miembros. En esta

\footnotetext{
75 CERUTTI, Mario. Empresarios españoles... Op. cit.

76 MATUTE, Ángel. Historia y evolución social... Op. cit., p. 13; LORENZO, Pablo. Historia de la Beneficencia... Op. cit., p. 395.

77 SARMIENTO, Érica. Galegos nos trópicos... Op. cit., p. 459.

78 Ibídem, p. 460.

79 GONZÁLEZ, Elda E. Tres inmigrantes, cuatro centros, un periódico... Las asociaciones españolas en Brasil. En: BLANCO, Juan A. (coord.). El asociacionismo en la emigración española a América. Salamanca: UNED-Zamora, Junta de Castilla y León, 2008, p. 384.
} 
última entidad la afiliación describió una curva ascendente a partir de la década de 1880 que le llevó a duplicar su número en el tiempo de la gran oleada, incluso durante la revolución. De esta manera, pasaron de los 269 en el primer año de vida a cuatrocientos veinte años después; en 1887 sobrepasaban los mil miembros, los tres mil en 1905 y los siete mil en 1920. Si bien en la década siguiente apenas crecieron, a la altura de 1936 rozaban ya los diez mil afiliados.

Más allá de su retórica discursiva de carácter caritativo, el cobro de cuotas regulares a los afiliados constituyó el principal recurso económico con el que contaron las sociedades para cubrir los gastos sanitarios y asistenciales, superior casi siempre al conjunto de donaciones, legados y testamentarías, que suponían un complemento de los ingresos ${ }^{80}$. Durante las primeras décadas, la función asistencial predominó en las dos sociedades sobre la cobertura médico-sanitaria: suministrar pequeños auxilios económicos a inmigrantes, buscar colocación a recién llegados, repatriar a enfermos crónicos y otras tareas similares fue todo lo que sus modestas arcas alcanzaron a cubrir ${ }^{81}$. Ambas subsistieron con una afiliación relativamente baja, recursos escasos y, cuando se podía, mediante la renta de pequeños espacios en hospitales locales o incluso en casas particulares de los socios fundadores acondicionadas para la atención médica ${ }^{82}$.

La memoria de la sociedad establecida en Río de 1881 enlistaba en primer lugar a los socios que habían recibido beneficencia durante el año; pasaba a nombrar a los socios socorridos "con designación de los Sñrs. miembros por quienes lo fueron", y finalmente también a los españoles que no pertenecían a la Sociedad, pero aun así habían sido socorridos. Estas cifras parecen indicar que la capacidad asistencial de esta entidad todavía era bastante reducida veinte años después de iniciada su andadura ${ }^{83}$.

La Memoria más cercana a esta de las halladas en la Sociedad de Ciudad de México, la de 1887, recogía el trabajo realizado en la Casa de Salud y Asilo a lo largo del año: ciento sesenta enfermos, 34 asilados y tres jubilados. El establecimiento disponía entonces de 28 camas para sus socios enfermos. Claramente la segunda institución había dado pasos importantes en cuanto a la cobertura sanitaria que la primera estaba todavía muy lejos de implantar. Un año antes, la de México había inaugurado su propio cementerio, el denominado Panteón Españo| ${ }^{84}$.

\footnotetext{
80 Solo disponemos de una memoria para el caso de Río, mientras que en Ciudad de México véase el trabajo de Gil Lázaro sobre las finanzas de la institución. Memoria de la Sociedad Española de Beneficencia. Río de Janeiro. Typ. De G. Leuzinger \& Filhos, 1881, pp. 1-2. GIL LÁZARO, Alicia. Inmigración y retorno... Op. cit., pp. 176-184.

81 LORENZO, Pablo. Historia de la Beneficencia... Op. cit., p. 421.

82 GIL LÁZARO, Alicia. Inmigración y retorno... Op. cit., pp. 160-161.

${ }^{83}$ Trece beneficiados (solamente uno aclaraba que se le había concedido "pasaje a Europa"), cinco mujeres pensionistas, dieciocho socorridos (por cuatro 'socorredores') y nueve personas socorridas sin pertenecer a la sociedad, cinco de ellas mujeres. Memoria de la Sociedad Española de Beneficencia. Río de Janeiro, pp. 4-6.

${ }^{84}$ Memoria de la Sociedad Española de Beneficencia. Ciudad de México. México, 1887, p. 11.
} 
Las sedes institucionales también tardaron en llegar. La Junta directiva de la sociedad de Ciudad de México se reunía en el local social del Casino Español y a partir de 1876, cuando finalmente pudo comprar su primer edificio destinado a hospital, en una de sus salas. Por su parte, en el libro conmemorativo de los 150 años de la Sociedad de Beneficencia Española de Río se relata que, en los primeros años de funcionamiento, la sociedad se reunía regularmente en casa de alguno de los socios y que más tarde lo hicieron en el Club Fluminense, una sociedad al parecer utilizada por la élite de la capital y frecuentada por la familia imperial. Algunos de los españoles más encumbrados en la sociedad carioca lograron que su Beneficencia pudiera sesionar allí. No fue hasta 1901, cuatro décadas después de su creación, cuando se inauguró una sede en propiedad. A partir de entonces los esfuerzos institucionales se enfocaron en el objetivo de disponer de un hospital propio, algo que no lograrían hasta treinta años después, en $1928^{85}$.

Sabemos que la Sociedad de la capital mexicana, con una orientación mayor a la función sanitaria desde el inicio, ocupó salas en cuatro hospitales diferentes antes de organizar su propio sanatorio. La estabilidad y consolidación de la sociedad comenzó en el período porfiriano, cuando adquirieron el edificio ya citado y eso haría que caminaran hacia una actividad plenamente centrada en la cobertura médicosanitaria dirigida esencialmente a sus socios, quedando la tarea asistencial relegada en la práctica a un plano menor, aunque siguiera fungiendo como eje de su fundamento discursivo, tal y como afirma Gil Lázaro ${ }^{86}$. A principios de siglo el hospital se había quedado muy pequeño y en mal estado para la demanda creciente de servicios médicos de una colonia en crecimiento, por lo que la Sociedad en México intentó comprar un terreno para edificar otro sanatorio desde la primera década del XX. Sin embargo, hasta 1932 no pudo inaugurarse ese segundo hospital, tras ocho años de obras y dificultades financieras tales que amenazaron con paralizarlas varias veces ${ }^{87}$. Algo muy similar ocurrió en la sociedad de Río. En 1917, compraron una parcela ubicada en el barrio de São Cristovão. Sin embargo, la construcción del hospital nunca llegó a verificarse y en 1928 se adquirió el edificio de la Casa de Salud Criciúma. La acondicionaron y ampliaron las estancias, crearon una sala de farmacia y otra destinada a laboratorio de análisis clínicos ${ }^{88}$.

En las décadas siguientes, bajo el influjo científico y tecnológico europeo y estadounidense, las dos beneficencias emprendieron la modernización de sus instalaciones y sus sistemas de gestión y administración, ampliando la cobertura primero a mujeres y niños, en el caso de la de Ciudad de México y a no españoles en Río. Así, en esta última, para incrementar el número de enfermos firmaron convenios con asociaciones como la que agrupaba a los conductores, a los que se les ofrecía una reducción del precio de la estancia diaria en el hospital ${ }^{89}$.

En las décadas centrales del siglo, este proceso de modernización confirió un carácter empresarial y tecnocrático a las sociedades que sería de gran ayuda y

\footnotetext{
85 Sociedade Espanhola de Beneficencia. Hospital Espanhol. Sociedade Espanhola de Beneficencia. 150 años de História. Rio de Janeiro: Sociedade Espanhola de Beneficencia, 2009, pp. 22-23.

${ }^{86}$ GIL LÁZARO, Alicia. Inmigración y retorno... Op. cit., pp. 185-192.

${ }_{87}$ CARREÑO, Alberto M. Los españoles en México... Op. cit., pp. 152-160.

88 Sociedade Espanhola de Beneficencia. Hospital Espanhol... Op. cit., pp. 43-51.

89 lbídem.
} 
preparación para las transformaciones posteriores, introduciendo prácticas médicas, terapéuticas, hospitalarias y de higienización modernas. La reducción progresiva de la llegada de inmigrantes en la segunda mitad del siglo XX y la ampliación de los sistemas públicos de salud obligaron a las benéficas a expandir su afiliación, de modo que también la de México aceptaría la inclusión de mexicanos y otros extranjeros. Esto constituyó el primer paso hacia la conversión de los dos hospitales sustentados por las instituciones españolas en instituciones sanitarias de lujo abiertas sencillamente a quien pudiera pagar sus servicios sin más condicionamiento que el nivel económico ${ }^{90}$.

El Grupo Hospital Español de México es un ejemplo del desarrollo corporativo reciente de estas instituciones. Nació en 2005 con la firma de un convenio de alianza estratégica de siete hospitales privados establecidos en diferentes ciudades de la República (Ciudad de México, Pachuca, Torreón, Veracruz, Puebla, San Luis Potosí y Tampico), cuyo elemento en común es que todos ellos fueron antiguas Sociedades Españolas de Beneficencia y con el objetivo de competir en el pujante mercado de las empresas sanitarias privadas (como Hospital Ángeles o Médica Sur). Desde entonces han mantenido una comunicación y encuentros periódicos, así como contactos con otros hospitales españoles del continente con vistas a crear una red latinoamericana.

\section{Conclusión}

Las comunidades migratorias españolas de Río de Janeiro y de Ciudad de México reúnen algunas características que hace posible su comparación en el tiempo. La más importante es que ambas crearon en una fecha muy temprana del siglo XIX un organismo benéfico para proporcionar asistencia a los inmigrantes que lo necesitaran. Para la institución de Ciudad de México esto fue posible por la existencia de una pequeña y poderosa élite que se había enriquecido gracias a los préstamos realizados a un convulso y endeudado Estado mexicano de mediados de siglo. Se trataba de un segmento privilegiado de la antigua sociedad colonial que había salvado la crisis de la independencia sin tener que irse del país (o pudiendo volver pronto) y que había recuperado sus anteriores actividades empresariales y sus propiedades o había podido rehacerlas relativamente rápido. Para la institución de Río, por otra parte, el grupo que la había creado, conformado por una mayoría gallega, constituía una corriente migratoria que a la vista de los pobladores cariocas se hallaba subsumida bajo el flujo mayor de portugueses, confundiéndose con él por su similitud. No había sido en ningún momento la corriente principal y su cercanía cultural a los lusitanos del norte había provocado esta supuesta invisibilidad, algo que se percibe tanto en algunas de las fuentes primarias como en la vida cotidiana de la urbe, las similares oportunidades laborales y los muchos prejuicios. Sin embargo, supieron crecer en medio de una sociedad en crecimiento, una ciudad abierta, cosmopolita y mestizada, mezclándose con las clases populares y compitiendo por los mercados ambulantes junto a negros exesclavos, italianos, cariocas y otros extranjeros. De ellos despuntaría una élite bien posicionada que 90 Disponible en <https://www.hespanol.com/ index.php/grupo-hospital-espanol>. [Fecha de consulta:
17-09-2020]. 
siguió los modelos portugueses a la hora de generar sus propias asociaciones asistenciales.

Aunque la labor estrictamente caritativa en los dos casos fue pequeña frente a la oferta de servicios mutuales con cuotas obligatorias que se terminaron imponiendo, las dos sociedades de beneficencia mantuvieron un discurso institucional basado en los principios cristianos de la caridad, la jerarquización interna y la gestión y dirección en manos de la élite económica del grupo migratorio. Hasta aquí no es un perfil exclusivo de las dos asociaciones comparadas, sino que, a grandes rasgos, este fue el esquema organizativo de la mayor parte de las beneficencias implantadas en los países de América Latina receptores de población inmigrante española durante la gran oleada del último tercio del siglo XIX y las primeras décadas del XX.

Tal vez lo más significativo de esta comparación es que a pesar de sostenerse sobre bases sociales, económicas y doctrinales similares, las trayectorias de ambas fueron muy diferentes. La sociedad en Ciudad de México experimentó un crecimiento en sus afiliados constante en sus primeros cien años de vida, mientras que la de Río este avance fue mucho más modesto, si nos atenemos a las escasas fuentes con las que hemos podido medir esta variable. También la primera acumuló un patrimonio mucho más rápida y fulgurantemente que la segunda, lo que le permitió hacer mucho antes la transición de una actividad discretamente asistencial hacia un modelo de institución volcada a la cobertura sanitaria y muy en menor medida asistencial. Respondía así al principio mutual de atender únicamente a sus asociados y elegir el perfil de sus miembros entre aquellos que en mejores condiciones estaban de pagar sus cuotas sin hacer un uso excesivo de sus servicios. Solo un grupo económicamente muy potente podía estar detrás de un crecimiento institucional así, lo que pone el contrapunto a las dos sociedades.

Ambas consiguieron modernizar sus unidades hospitalarias en las décadas centrales del siglo XX, en un momento en el que el flujo migratorio europeo se agotó y la actividad sanitaria ya no pudo sostenerse más sobre las mismas bases sociales que la habían creado. La situación obligaba a abrir las puertas a todo aquel que quisiera acudir y que pudiera pagar y dio paso a una renovación en profundidad del sentido de asociación de emigrantes bajo el que las dos sociedades habían sido creadas. Su éxito se cifra, por último, no solo por su longevidad, sino por un funcionamiento empresarial eficiente y racional, que supo adaptarse ante contextos históricos y migratorios cambiantes.

\section{Bibliografía}

ÁLVAREZ, Oscar. Rebuilding virtually the homeland: immigrants' institutions in host countries, between integration and self-preservation. En: ÁLVAREZ, Oscar (ed.). Organización, identidad e imagen de las colectividades vascas de la emigración (siglos XVI-XXI). Bilbao: Universidad del País Vasco, Servicio de Publicaciones, 2010, pp. 73-92.

AZEVEDO. André Nunes. A grande reforma urbana do Rio de Janeiro: Pereira Passos, Rodrigues Alves e as ideias de civilização e progresso. Rio de Janeiro: Editora PUC-Rio; Mauad X, 2017. 
BAILY, Samuel. Las sociedades de ayuda mutua y el desarrollo de una comunidad italiana en Buenos Aires, 1858-1918. Desarrollo Económico. 1982, vol. 21, n. 184, pp. 485-514.

BERNARDO DE QUIRÓS, Pilar. EI 'momento mutualista' en la formulación de un sistema de protección social en Argentina: socorro mutuo y prevención subsidiada a comienzos del siglo XX. Revista de Indias. 2013, n. 257, pp. 157192.

BLANCO, Juan A. Desarrollo de la identidad regional: el asociacionismo español en Cuba. En: BLANCO, Juan A. y DACOSTA, Arsenio (eds.). El asociacionismo de la emigración española en el exterior: significación y vinculaciones. Zamora: UNED, 2014, pp. 129-150.

BLOCH, Marc. Pour une historie comparée des sociétes européennes. Revue de synthèse historique. 1928, n. 46, pp. 15-20.

CARREÑO, Alberto M. Los españoles en México (Un siglo de Beneficencia). México, 1942.

CERUTTI, Mario. Empresarios españoles y sociedad capitalista en México (18401920). Gijón: Archivo de Indianos, 1995, pp. 83-99.

DANZA GRECO, Patricia. Un olhar sobre o pasado. As origens da SEB e da Imigração española no Brasil. Revista do Hospital Espanhol. Edição Especial. Abr. 2010.

DE CRISTÓFORIS, Nadia. Bajo la cruz del sur: gallegos y asturianos en Buenos Aires (1820-1870). Coruña: Fundación Pedro Barrié de la Maza, 2010.

FARÍAS, Ruy. La participación gallega en los inicios del asociacionismo mutualista español en Barracas al Sud (1862-1891). En: BLANCO, Juan A. y Dacosta, Arsenio (eds.). El asociacionismo de la emigración española en el exterior: significación y vinculaciones. Zamora: UNED, 2014, pp. 425-442

FERNÁNDEZ, Alejandro. Mutualismo y asociacionismo. En: VIVES, Pedro; VEGA, María J. y OYAMBURU, Jesús (coords.). Historia general de la emigración española a lberoamérica. Vol. 1. Madrid: Historia 16, 1992, pp. 331-357.

FERNÁNDEZ, Alejandro. El asociacionismo español en Argentina: una perspectiva de largo plazo. En: BLANCO, Juan A. y DACOSTA, Arsenio (eds.). El asociacionismo de la emigración española en el exterior: significación y vinculaciones. Zamora: UNED, 2014, pp. 209-235.

FERNÁNDEZ, Alejandro. Inmigración y mutualismo en el largo plazo: el Montepío de Montserrat y las asociaciones catalanas en Buenos Aires. En: BLANCO, Juan A. y DACOSTA, Arsenio (eds.). El asociacionismo español de una inmigración diferenciada. Madrid: Polifemo, 2020, pp. 241-262. 
FERNANDEZ, Alejandro. El asociacionismo español en el cono sur de América: una visión comparativa. En: BLANCO, Juan A. y Dacosta, Arsenio (eds.). El asociacionismo de la emigración española en el exterior: significación y vinculaciones. Zamora: UNED, 2014, pp. 209-233.

GARCÍA, Clara. Sociedad, crédito y cofradía en Nueva España a fines de la época colonial: el caso de Nuestra Señora de Aranzazu. Historias. 1983, pp. 53-68.

GIL LÁZARO, Alicia. Las Sociedades de Beneficencia Españolas de México, Puebla y Veracruz en el primer tercio del siglo XX. En: SARMIENTO, Érica y EVANGELHO, Dabiel (eds.). Imigração ibérica e associativismo. Identidade e laços de solidariedade. Rio de Janeiro: Editora Autografia, 2021 [en prensa].

GIL LÁZARO, Alicia. Extranjeros perniciosos. Infractores y delincuentes españoles en la Ciudad de México, 1910-1936. Revista de Indias. 2003, vol. LXIII, n. 228, pp. 477-494.

GIL LÁZARO, Alicia. Inmigración y retorno. Españoles en la Ciudad de México, 19001936. Madrid: Marcial Pons, Universidad de Alcalá, 2015.

GONZÁLEZ, Elda y REDONDO, Emilio. Desafíos históricos del asociacionismo español en Brasil: siglos XIX-XXI. En: BLANCO, Juan A. y DACOSTA, Arsenio (eds.). El asociacionismo español de una inmigración diferenciada. Madrid: Polifemo, 2020, pp. 121-140.

GONZÁLEZ, Elda E. Tres inmigrantes, cuatro centros, un periódico... Las asociaciones españolas en Brasil. En: BLANCO, Juan A. (coord.). El asociacionismo en la emigración española a América. Salamanca: UNEDZamora, Junta de Castilla y León, 2008, pp. 365-387.

GUTIÉRREZ, Adriana. El Casino Español de México. 140 años de historia. México: Editorial Porrúa, 2004.

GUTIÉRREZ, Mar. La nación española and the Centro de Dependientes: the silenced projects of the Spanish colony in the city of México (1900-1901). En: NAVARRO AZCUE, Concepción y PRADO, Gustavo H. (coords.). Intellectualism and migration: international networks of European culture in America (19th-21st). 2016, pp. 195-216.

GUTIÉRREZ, Mar. Salud, beneficencia y mutualismo: la colonia española en la ciudad de México durante el Porfiriato. História, Ciéncias, Saúde - Manguinhos. 2021, v. 28, n. 2, pp. 437-454.

JARQUÍN, María T. La población española en la Ciudad de México. En: LIDA, Clara (coord.). Tres aspectos de la presencia española en México durante el Porfiriato. México: El Colegio de México, 1981, pp. 178-223.

KLAUMANN, Marília. Associativismo étnico hispano-brasileiro: histórico e 
perspectiva atual. En: BLANCO, Juan A. y DACOSTA, Arsenio (eds.). El asociacionismo español de una inmigración diferenciada. Madrid: Polifemo, 2020, pp. 141-161.

KLEIN, Herbert. La inmigración española en Brasil. Gijón: Archivo de Indianos, 1996.

KUNTZ, Sandra. De las reformas liberales a la gran depresión, 1856-1929. En: KUNTZ, Sandra (coord.). La economía mexicana, 1519-2010. México: El Colegio de México, 2012, pp. 305-353.

LAHMAYER, Eulália. Historia de Rio de Janeiro (do capital comercial a o capital industrial e financiera). Rio de Janeiro: IBMEC, 1978, pp. 450-503.

LEVINE, Philippa. Is comparative history possible? History and theory. 2014, n. 53, pp. 331-347.

LIDA, Clara. Inmigración y exilio. Reflexiones sobre el caso español. Madrid: Siglo XXI Editores, 1997.

LORENZO LAGUARTA, Pablo. Historia de la Beneficencia española en México (síntesis). México: La Impresora Azteca, 1955.

MATUTE, Ángel. Historia y evolución social de la Beneficencia Española en México. México: s.p.i., 1966.

MORALES RAYA, Eva. El asociacionismo de la emigración española en Paraguay (1870-1932): los casos de la Sociedad Española de Socorros Mutuos de Asunción del Paraguay y el Centre Catalá de Asunción. En: BLANCO, Juan A. y DACOSTA, Arsenio (eds.). El asociacionismo de la emigración española en el exterior: significación y vinculaciones. Zamora: UNED, 2014, pp. 371-383.

MORALES, María D. La expansión de la ciudad de México en el siglo XIX. El caso de los fraccionamientos. En: MORALES, María D. [et al.]. Investigaciones sobre la historia de la ciudad de México III. México: INAH, 1978, pp. 189-200.

MORENO, Javier. La otra España. Empresas y empresarios españoles en la ciudad de México durante la Revolución. América Latina en la Historia Económica. 2007, n. 27, pp. 111-156.

MOYA, José C. Los inmigrantes y sus asociaciones: una perspectiva histórica global. Apuntes de investigación del CECYP. 2008, n. 13, pp. 11-50.

NUNES DE AZEVEDO, André y SARMIENTO, Érica. O progresso no "Facer as Américas". Sociabilidade e práticas associativas dos imigrantes ibéricos no alémmar (1890-1930). En: SARMIENTO, Érica y PEREIRA, Leandro (eds.). Abordagens cruzadas no mundo Atlântico, Relações contemporâneas entre a Península Ibérica e a América Latina. Rio de Janeiro: EDUPE, Autografia, 2019, pp. 23-42. 
NUNES DE AZEVEDO, André y SARMIENTO, Érica. Las 'parroquias' en la ciudad de Rio de Janeiro: vivienda y trabajo de los gallegos en el barrio de San Antonio (1850-1930). Andes. 2017, vol. 28, n. 2.

NUNES AZEVEDO, André. Da Monarquía a República. Um estudo dos conceitos de progresso e civilização na cidade do Rio de Janeiro (1868-1906) [tese de Doutorado]. Rio de Janeiro: Pontifícia Universidade Católica, 2003.

NúÑEZ, Xosé M. y GARCÍA, Marcela (eds.). Patrias lejos de casa. Nacionalismo español, migración y exilio en Europa y América (1870-1975). Zaragoza: Prensas Universitarias, 2020.

NÚÑEZ, Xosé M. Migrants associations: the Spanish transatlantic experience, 18701970. Social History. 2016, vol. 41, n. 2, pp. 136-154.

NúÑEZ, Xosé M. Las patrias ausentes. Estudios sobre historia y memoria de las migraciones ibéricas (1830-1960). Gijón: Genueve, 2014.

PASCHOAL GUIMARAES, María L. Espanhóis no Rio de Janeiro (1880-1914). Contribuição à historiografia brasileira [tese de Doutorado]. Universidade do Rio de Janeiro, 1988.

PÉREZ HERRERO, Pedro. Algunas hipótesis de trabajo sobre la inmigración española a México: Ios comerciantes. En: LIDA, Clara (coord.). Tres aspectos de la presencia española en México durante el Porfiriato. México: El Colegio de México, 1981, pp. 103-139.

PORTO, Ángela [et al.]. (orgs.). Historia de la salud de Río de Janeiro. Instituciones y patrimonio arquitectónico (1808-1958). Rio de Janeiro: Fiocruz, 2008.

RAMOS, Jon A. Mutualismo e identidad: ensayo de periodización de la Asociación Vasco-Navarra de Beneficencia de La Habana, 1877-2012. En: BLANCO, Juan A. y DACOSTA, Arsenio (eds.). El asociacionismo de la emigración española en el exterior: significación y vinculaciones. Zamora: UNED, 2014, pp. 47-50.

SALAZAR, Delia. Las cuentas de los sueños. La presencia extranjera en México a través de las estadísticas nacionales, 1880-1914. México: Conaculta, 2010.

SARMIENTO, Érica y EVANGELHO, Dabiel (eds.). Imigração ibérica e associativismo. Identidade e laços de solidariedade. Rio de Janeiro: Editora Autografia, 2021.

SARMIENTO, Érica. Galegos nos trópicos. Invisibilidade e presença da imigração galega no Rio de Janeiro (1880-1930). Porto Alegre: Edipucrs, 2017.

SARMIENTO, Érica y MEDEIROS DE MENEZES, Lená. Aspectos da desordem urbana: imigrantes ibéricos e a contravenção no Rio de Janeiro republicano (1880-1930). Estudos Ibero-americanos. 2015, vol. 41, n. 1, pp. 164-180. 
Sociedade Espanhola de Beneficencia: 150 años de história. Rio de Janeiro: Sociedade Espanhola de Beneficencia, 2009.

SPECKMAN, Elisa y AGOSTONI, Claudia. Modernidad, tradición y alteridad. La ciudad de México en el cambio de siglo. México: UNAM, 2000.

VÁZQUEZ, Alexandre. Emigrantes galegos, transportes e remesas (1830-1930). A Coruña: Fundación Barrié, 2015.

VILLAR, F. Directorio de la colonia española. México: s.n., 1937.

WEINBREN, Daniel. Supporting Self-Help, Charity, Mutuality and Reciprocity in Nineteeth-Century Britain. En: HARRIS, Bernard y BRIDGEN, Paul (coords.). Charity and Mutual Aid in Europe and North America since 1800. New York: Routledge, 2007, pp. 67-88.

YÁÑEZ, César. Saltar con red. La temprana emigración catalana a América, ca. 1830-1870. Madrid: Alianza, 1996.

ZAMORANO, Víctor. De agentes del progreso a elementos del desorden: inmigrantes españoles y exclusión social en Río de Janeiro (1880-1930) [tesis doctoral]. Salamanca: Universidad de Salamanca, 2010. 